OPEN ACCESS

Edited by:

Luciano Bosso,

Università degli Studi di Napoli

Federico II, Italy

Reviewed by:

Francesca Raffini,

University of Ferrara, Italy

Koh Hasegawa

Japan Fisheries Research and

Education Agency (FRA), Japan

*Correspondence:

Baran Yoğurtçuoğ/u

yokbaran@gmail.com

Specialty section:

This article was submitted to

Conservation and Restoration

Ecology,

a section of the journal

Frontiers in Ecology and Evolution

Received: 28 August 2020 Accepted: 28 December 2020

Published: 22 January 2021

Citation:

Yoğurtçuoğ/u B, Bucak T, Ekmekçi FG Kaya $C$ and Tarkan AS (2021)

Mapping the Establishment and Invasiveness Potential of Rainbow

Trout (Oncorhynchus mykiss) in

Turkey: With Special Emphasis on the Conservation of Native Salmonids.

Front. Ecol. Evol. 8:599881

doi: 10.3389/fevo.2020.599881

\section{Mapping the Establishment and Invasiveness Potential of Rainbow Trout (Oncorhynchus mykiss) in Turkey: With Special Emphasis on the Conservation of Native Salmonids}

\author{
Baran Yoğurtçuoğlu ${ }^{1 *}$, Tuba Bucak ${ }^{2}$, Fitnat Güler Ekmekçi ${ }^{1}$, Cüneyt Kaya ${ }^{3}$ and \\ Ali Serhan Tarkan ${ }^{4,5}$ \\ ${ }^{1}$ Freshwater Fish Biology and Ecology Laboratory, Department of Biology, Faculty of Science, Hacettepe University, Ankara, \\ Turkey, ${ }^{2}$ The Nature Conservation Centre (DKM), Ankara, Turkey, ${ }^{3}$ IChthyological Research Laboratory, Faculty of Fisheries \\ and Aquatic Sciences, Recep Tayyip Erdogan University, Rize, Turkey, ${ }^{4}$ Ecology \& Invasion Unit, Department of Basic \\ Sciences, Faculty of Fisheries, Muğla Sıtkı Koçman University, Mugla, Turkey, ${ }^{5}$ Department of Ecology and Vertebrate \\ Zoology, Faculty of Biology and Environmental Protection, University of Łódz, Łódz, Poland
}

Rainbow trout (Oncorhynchus mykiss) has become by far the most frequently farmed freshwater fish species in Turkey, whereas very little is known about its establishment and invasiveness potential. We explored this potential through a combination of Maxent habitat suitability model and the Aquatic Species Invasiveness Screening Kit (AS-ISK) on the river basin scale by generating an overall risk score (ORS). The outcome of this approach was also incorporated with the spatial analysis of native salmonid species by generating a relative vulnerability score (RVS) to prioritize susceptibility of native species (or populations) and to propose risk hotspots by identifying their potential geographic overlap and interaction with O. mykiss. Results suggest that the northern basins (Eastern Black Sea, Western Black Sea and Marmara basins) are the most suitable basins for $O$. mykiss. According to the Basic Risk Assessment (BRA) threshold scores, O. mykiss is classified as "high risk" for 3 (12.0\%) of the 25 river basins screened (Western Black Sea, Eastern Black Sea and Maritza-Ergene), and as "medium risk" for the remaining basins. The climate change assessment (CCA) scores negatively contributed the overall invasiveness potential of 0 . mykiss in 22 (88.0\%) of the river basins and resulted in zero contribution for the remaining three, namely Aras-Kura, Çoruh river and Eastern Black Sea. The ORS score of river basins was lowest for Orontes and highest for Western Black Sea, whereas it was lowest for Konya-closed basin and highest for Eastern Black Sea, when CCA was associated. The micro-basins occupied by Salmo rizeensis had the highest mean habitat suitability with O. mykiss. Among the all species, S. abanticus had the highest RVS, followed by S. munzuricus and S. euphrataeus. The overall outcome of the present study also suggests that the establishment and invasiveness potential of 


\begin{abstract}
O. mykiss may decrease under future (climate warmer) in Turkey, except for the northeast region. This study can provide environmental managers and policy makers an insight into using multiple tools for decision-making. The proposed RVS can also be considered as a complementary tool to improve IUCN red list assessment protocols of species.
\end{abstract}

Keywords: aquaculture, aquatic species invasiveness screening kit, Maxent habitat suitability model, climate change, invasiveness potential

\section{INTRODUCTION}

The spectrum of the impacts of invasive species on overall biodiversity is so wide that ranges from behavioral changes of native species to entire collapsing of ecosystem services and extinction of native taxa (Charles and Dukes, 2008; Simberloff et al., 2013; Gallardo et al., 2016). The economic burden is also significant, reaching billions of dollars all over the world, particularly in the United States, Australia and Western Europe (Pimentel et al., 2005; Hoffmann and Broadhurst, 2016; Bertolino et al., 2020). Therefore, environmental agencies have struggled to manage the introduction and impact of invasive species by strengthening their legislations and policies for nature conservation and socio-economic issues globally (Copp et al., 2005a). The most important step of this endeavor is to predict species' invasiveness- the capacity of a species to reproduce, spread from its place of introduction, and establish in new locations (Rejmánek, 2011)-, and which sources of introductions are likely to become more prominent under current and future climatic and socio-economic conditions (Rahel and Olden, 2008; Banerjee et al., 2019; Raffini et al., 2020). Escape from farms, breeding/cultivation facilities, gardens or laboratories into natural systems constitute important and unregulated sources of introductions by which animals and plants become invasive (Hulme et al., 2008; Essl et al., 2015). Concordantly, the majority of aquatic inland species introductions are considered as escapees from aquaculture, which have resulted in serious aquatic invasions worldwide (Ju et al., 2020). This pathway is even more crucial for countries like Turkey where aquaculture predominantly depends on the farming of non-native species and represents approximately $25 \%$ (by value) of the total production of the fishery sector (TUIK, 2014). This pathway is also highly important due to Turkey's current efforts to align with international quality standards (e.g., European Commission, 2014).

In Turkey, inland fisheries constitute a considerable proportion of the total fish production both by capture (5\%) and aquaculture (44\%) and are concentrated in inland lakes (including reservoirs) and the coastal lagoons (FAO, 2019). Aquaculture dates back to the late 1960s (Lök et al., 2018) with farming of rainbow trout (Oncorhynchus mykiss) and common carp (Cyprinus carpio), with non-native O. mykiss being the most frequently farmed aquaculture species over the past few decades. According to the up-to-date aquaculture statistics provided by the Turkish General Directorate of Fisheries and Aquaculture, the species is now being farmed in 74 of the 81 provinces with $\sim 1,550$ farms which are mostly located in inland waters (dataset available at https://www.tarimorman.gov.tr/BSGM/ Belgeler/Icerikler/Su\%20\%C3\%9Cr\%C3\%BCnleri\%20Yeti\%C5 $\% 9$ Ftiricili\%C4\%9Fi/Su-Urunleri-Tesisleri-2019.pdf). On one hand, O. mykiss has been listed as one of the 100 worst invasive alien species identified globally by the IUCN (Lowe et al., 2000) and ranks high in the list of the top 18 fish species that cause severe ecological impacts, compiled from establishment and impact assessment data contained in FISHBASE (Casal, 2006). Therefore, the impact mechanisms of the species, which can be summarized as competition/monopolizing resources, hybridization with native salmonids and predation, are very well-documented (Scott and Irvine, 2000; Weigel et al., 2003; Stanković et al., 2015). On the other hand, a recent review of risk screenings conducted for the eastern Mediterranean region (Vilizzi et al., 2019), indicated that the potential of O. mykiss to be a highly invasive species is lower (i.e., yielded moderate risk) than suggested by previous risk assessments where future climate change may negatively affect its spread and impact. In a recent study, the threats posed by O. mykiss in Greece has also been reported to be lower than suggested by recent risk assessments (Koutsikos et al., 2019), though its self-sustaining population has become established on the Island of Crete (Stoumboudi et al., 2017). In contrast, Hasegawa (2020) demonstrated that brown trout in some Japanese islands show higher invasiveness than that was suggested in previous studies, and this was associated with the similarities in the life histories of native salmonids in Japan. These results, therefore, indicate that the current approaches in risk assessments tend to under- or overestimate the potential risk of salmonids, probably due to the lack of integrated quantitative habitat and niche suitability (or species distribution) and climate change models. Furthermore, selecting coarse scales for the risk assessments (e.g., biogeographical, climatic, or country scale) especially for geographically heterogeneous risk assessment (RA) areas (e.g., Turkey) may result in under- or overestimated risk scores.

Although O. mykiss has had a relatively long history in aquaculture in Turkey (Tarkan et al., 2015), escapes from farms, which are known to occur very frequently, have been poorly documented. Also, little is known on whether escapes have resulted in viable (or resilient) populations in natural habitats. These incidents are of great importance especially in Turkey, which covers the entire natural distribution of at least 13 native trout species, 6 of which are classified as threatened, 6 are not evaluated and only one is classified as least concern by the International Union for Conservation of Nature (IUCN). Despite this rich diversity of native salmonids in Turkish freshwaters, there remains a paucity of research exploring the 
habitat suitability and establishment risk of O. mykiss, which may help to address its potential spatial overlap and interaction with native salmonids. Previous studies on the effects of $O$. mykiss aquaculture in Turkey have been focused on water quality of natural waters around the facilities (Demir et al., 2001; Cromey et al., 2002; Brooks et al., 2003), and there is only one study reported some adverse impacts of escapee rainbow trout in some streams (Biga peninsula, Çanakkale, NW Turkey) on native ichthyofauna through abundance, diet preferences and intraspecific feeding interactions (Ertürk-Gürkan and Yalçin Özdilek, 2019).

The main goal of this study was therefore 2-fold: to evaluate the establishment and invasiveness potential of $O$. mykiss in Turkey on the river basin scale, and to identify its geographic overlap probability with the native salmonid species of conservation concern. The first step was addressed by predicting the establishment potential of non-native O. mykiss in Turkey following the habitat suitability approach using the Maxent species distribution modeling, and by assessing its invasiveness potential across the main river basins of Turkey using the Aquatic Species Invasiveness Screening Kit (AS-ISK). By collecting and assessing the available occurrence records of farm escapements, this study also has the potential to contribute to fill up the common gaps by minimizing possible inconsistencies between current and future invasiveness of species and current and projected risk assessments.

The second objective was met by conducting spatial analysis for documenting the distribution of native salmonids and for examining the suitability of their natural geographic range against O. mykiss. It is a well-known fact that cost-effective conservation of species requires prioritization. Therefore, to prioritize and categorize the sensitivity of native salmonids against the overlap and interaction (including hybridization) with rainbow trout, we proposed a metric by blending the benefited risk assessment approach with the spatial analysis of the native trout species. By this way, hotspots for potential hybridization and antagonistic interactions between the nonnative $O$. mykiss and the native trout species are also proposed. The overall outcome of the present study is also expected to provide environmental managers and stakeholders insight into the potential use of AS-ISK with habitat suitability models as an integrated set of decision-support tools for informing policy makers and for suggesting management options for the potential, existing and future undesired non-native fishes of aquaculture importance.

\section{MATERIALS AND METHODS}

\section{Habitat Suitability Model}

Since O. mykiss is a non-native species in Turkey, and no established populations have been officially confirmed yet, the distribution data of the species which is needed for calibration of the habitat suitability was downloaded from the Global Biodiversity Information Facility (GBIF, 2020). The spatial data represented the natural distribution of O. mykiss, which extends from Alaska to Mexico in the northwest of North America (Behnke, 1979; Crawford and Muir, 2008) (Figure 1).

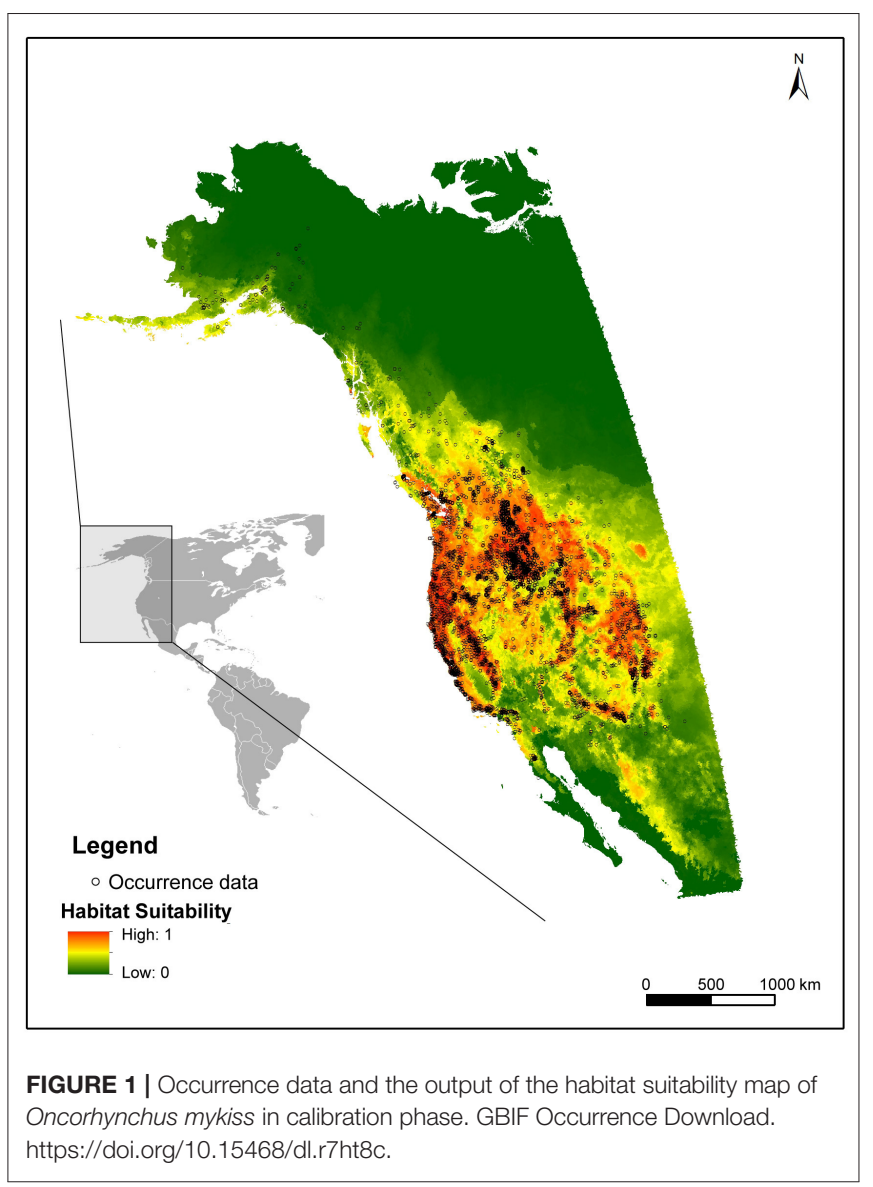

The occurrence data is comprised of 94,275 georeferenced records from 4,476 unique locations which were compiled from 40 published datasets covering this native range. To model the habitat suitability, common topographical and climatic parameters within BasinATLAS database were used and seven environmental variables were significant in terms of explaining the habitat suitability of O. mykiss. These variables are average annual minimum temperature, average annual maximum temperature, average annual temperature, slope, aridity index, elevation and precipitation. All these variables were examined on the basis of hydrological subunits (i.e., microbasin scale provided by the BasinATLAS Attributes) and the highest resolution of sub basin division (level 12) (Lehner and Grill, 2013) were used. Commonly used species distribution model Maxent (Phillips et al., 2006, Version 3.3.3) was employed to generate the habitat suitability of $O$. mykiss across Turkey with 10 -fold cross-validation method. Maximum iterations were set to 10,000 , random test percentage was 20 , and maximum number of background points were set as 10,000. For each run, 2,974 presence records were used for training, 743 records for testing and 12,590 points were used to determine distribution including both background points and presence points. First, the model was calibrated for North America (native range) for the occurrence data downloaded from GBIF and then, the calibrated model was projected for habitat suitability of $O$. 
mykiss in Turkey. Multivariate Environmental Similarity Surfaces (MESS, Elith et al., 2010) analysis, which were also embedded in Maxent software were applied to assess the similarity of the predictor variables between the training dataset (United States) and projection dataset (Turkey). The accuracy of the results was evaluated by True Skill Statistics (TSS) and the area under the receiver operating characteristic (ROC) curve (AUC), which are commonly used as threshold-independent measures for model performance (Manel et al., 2001; Allouche et al., 2006). These model evaluation statistics range between 0 and 1 for AUC and between -1 and 1 for TSS, where AUC and TSS values close to 1 indicates excellent model performances.

\section{Screening of Invasiveness}

Aquatic Species Invasiveness Screening Kit (AS-ISK) v2.2 (available at www.cefas.co.uk/nns/tools) was used to identify the invasiveness potential of $O$. mykiss. AS-ISK is a risk screening decision-support tool that is fully compliant with the "minimum standards" (Roy et al., 2018) for the assessment of nonnative species for the European Commission Regulation on the prevention and management of the introduction and spread of invasive alien species (European Union, 2014). This decisionsupport tool has already been used successfully to screen nonnative fishes in several RAs including biogeographic (Glamuzina et al., 2017; Tarkan et al., 2017a) and climatic risk RAs (Dodd et al., 2019). AS-ISK consists of 55 questions, which are grouped into 49 Basic Risk Assessment (BRA) and six Climate Change Assessment (CCA) questions to assess the biogeographical and historical traits of the taxon and its biological and ecological interactions. The BRA questions have two main sections: the Biogeography/Historical and the Biology/Ecology that are complemented by an additional six questions asking the assessor to assess how predicted future climate conditions are likely to affect their responses to Qs related to the risks of introduction, establishment, dispersal and impact. For each question in ASISK, the assessor must provide a response, justification and level of confidence. The screened species eventually receives both a BRA and a BRA+CCA (composite) score, which respectively range from -20.0 to 68.0 and from -32.0 to 80.0 (Dodd et al., 2019). AS-ISK scores $<1.0$ suggest that the species is unlikely to become invasive in the RA area and is therefore classified as "low risk" whereas higher scores classify the species as posing either a "medium risk" or a "high risk" of becoming invasive. The ranked levels of confidence $(1=$ low; $2=$ medium; $3=$ high; $4=$ very high) associated with each response in AS-ISK mirror the confidence rankings recommended by the International Programme on Climate Change (IPCC, 2005).

Turkey is divided into 25 main hydrological units which herein we called the river basins. For O. mykiss, AS-ISK assessments were undertaken at the river basin level to increase the resolution of the scores as much as reasonably possible. The assessments were carried out by a subset of co-authors, whose knowledge of the species is specialized to a certain region, namely the western basins were assessed by AST, the central and northern basins by BY, and the eastern and north-eastern basins by CK. All assessments then were peer-reviewed by all authors. A literature survey was carried out pertinent to the species and the RAs to obtain valid evidences for each of the question in the risk assessment panel. Although there is extensive peer-reviewed literature on the species itself, we mainly utilized review papers with relatively broader extent and some common databases (e.g., FishBase and Global Invasive Species Database) in which respectable and goal-directed information are available. Information on the general climate and future predictions inherent in the CCA questions were based on the Köppen-Geiger climate classification system (Peel et al., 2007).

The calibrated AS-ISK threshold score (i.e., 27.75) established for categorization of potential risk status of non-native freshwater fish species (i.e., distinguishing between high risk from low-tomedium risk) for whole Turkey (Tarkan et al., 2017b) was used in the present study for O. mykiss in the assessed river basins. However, as no BRA+CCA threshold in Tarkan et al. (2017a) was provided, Receiver Operating Characteristic (ROC) curve analysis (Bewick et al., 2004) was used to assess the predictive ability of AS-ISK to discriminate between non-native freshwater fish species posing a high risk and those posing a medium or low risk of being invasive for the RA area. For ROC curve analysis to be implemented, species need to be categorized a priori in terms of their documented invasiveness (i.e., non-invasive or invasive). Since this information is readily available in Tarkan et al. (2017a), we used it for a new threshold value calculation of BRA+CCA. Briefly, a ROC curve is a graph of sensitivity vs. 1 - specificity (or alternatively, sensitivity vs. specificity) for each threshold value, where in the present context sensitivity and specificity will be the proportion of a priori invasive and non-invasive species, respectively, that are correctly identified by AS-ISK as such. The Area Under the Curve (AUC) known as a measure of the accuracy of the calibration analysis typically ranges from 0.5 to 1 , and the closer to 1 the greater the veracity in differentiating between invasive and non-invasive species. When the test is $100 \%$ accurate, AUC is equal to 1 . Because both sensitivity and specificity are 1, and there are neither "false positives" (a priori non-invasive species classified as high risk, hence invasive) nor "false negatives" (a priori invasive species classified as low risk, hence non-invasive). Conversely, when the test is $0 \%$ accurate it means the AUC is equal to 0.5 , as it cannot discriminate between "true positives" (a priori invasive species classified as high risk, hence invasive) and "true negatives" (a priori noninvasive species classified as low risk, hence non-invasive).

Following ROC analysis, the best AS-ISK threshold value that maximizes the true positives rate and minimizes the false positives rate was determined using Youden's J statistic; whereas, the "default" threshold of 1 was set to distinguish between low risk and medium risk species (Copp et al., 2005b). ROC analysis was carried out with package pROC (Robin et al., 2011) for R x64 v4.0.0 (R Core Team, 2020) using 2000 bootstrap replicates for the confidence intervals of specificities, which were computed along the entire range of sensitivity points (i.e., $0-1$, at 0.1 intervals). The ranked levels of confidence $(1=$ low; $2=$ medium; $3=$ high; $4=$ very high) associated with each response in AS-ISK mirror the confidence rankings recommended by the International Programme on Climate Change (IPCC, 2005; see also Copp et al., 2016a). Based on the confidence level (CL) allocated to each response for a given basin, a confidence factor 
(CF) is obtained as:

$$
\sum\left(C L_{Q i}\right) /(4 \times 55)(i=1, \ldots, 55)
$$

where $\mathrm{CL}_{\mathrm{Q} i}$ is the $\mathrm{CL}$ for question $i(\mathrm{Q} i) ; 4$, is the maximum achievable value for confidence (i.e., very high: see above) and 55 is the total number of questions comprising the AS-ISK questionnaire. Based on the BRA and the CCA only, the $\mathrm{CL}_{\mathrm{BRA}}$ and $\mathrm{CL}_{\mathrm{CCA}}$ are also computed. The $\mathrm{CF}$ ranges from a minimum of 0.25 (i.e., all 55 questions with CL equal to 1 ) to a maximum of 1 (i.e., all 55 questions with CL equal to 4). Two additional $\mathrm{CFs}$ are also computed, namely the $\mathrm{CF}_{\mathrm{BRA}}$ and the $\mathrm{CF}_{\mathrm{CCA}}$, as per the CL.

\section{Overall Assessment}

We employed an integrated approach in which both habitat suitability and the invasiveness potential are jointly considered in evaluating the overall risk of O. mykiss. A common way for estimating overall risk exposure is to multiply probability and impact. Here, we consider habitat suitability (Maxent scores) as the establishment probability of O. mykiss; whereas, we considered invasiveness screening outputs as the impact. To obtain the possible maximum resolution to incorporate establishment probability and the invasiveness screening was to estimate the habitat suitability and to screen the invasiveness potential on the same scale. To this end, we selected each river basin as RA area, and performed AS-ISK separately for all river basins. After that, to calculate the descriptive statistics of Maxent habitat suitability values for each of the river basin, we aggregated the micro-basin level habitat suitability values. Therefore, the overall risk score (ORS) of basin " $i$ " is calculated by the following equation;

$$
\mathrm{ORS}_{i}=\text { Maxent }_{i} \times \text { AS-ISK }_{i}
$$

Where "Maxent" is the average habitat suitability of O. mykiss for basin " $i$ ", and "AS-ISK" is the invasiveness screening score of O. mykiss for basin " $i$ ". We generated two ORSs for each basin, one is based on BRA ( $\left.\mathrm{ORS}_{\mathrm{BRA}}\right)$ and the other is on BRA+CCA $\left(\mathrm{ORS}_{\mathrm{BRA}+\mathrm{CCA}}\right)$ scores.

To propose risk hotspots and to prioritize native endemic trout, we estimated their extent of occurrence (EOO) by calculating the area $\left(\mathrm{km}^{2}\right)$ of minimum convex polygon around all present native occurrences of a species. We also took the number of independent populations (IP) of a species into account. IP was primarily determined by considering the number of hydrologically independent river catchments that actually occupied by the native trout species. Secondly, each of the discrete (or isolated) populations within the same river catchment, if available, are regarded as IP. Following this, we complemented the assessment of their occurrence ranges with the habitat suitability of $O$. mykiss. For this, the habitat suitability of $O$. mykiss was estimated for the all of the micro-basins which bear at least one site-scale record of a native salmonid species. The EOO calculations of the native species were based on these site-scale records and achieved using the spatial analysis module of RAMAS Red List Pro software (Akçakaya and Root, 2007). To avoid overestimating the EOOs for the species with multiple discrete populations that dispersed over different river basins, EOOs were calculated separately for each river basin and then were summed up to obtain the species' EOO. The occurrence datasets of the native trout species were derived from the available recent literature (Turan et al., 2010, 2011, 2012, 2014a,b; Turan et al., 2017, 2020; Yoğurtçuoğlu et al., 2020). The confirmed occurrences of $O$. mykiss from natural water bodies was also compiled from both published literature and data obtained by our own field explorations, which were dotted on the habitat suitability map together with the occurrence of native salmonids in order to visually match the model outcome and the real escape cases of O. mykiss.

To prioritize the native salmonid species and their habitats against the potential of establishment and invasiveness of $O$. mykiss, we proposed a Relative Vulnerability Score (RVS) based upon blending the ORS, Maxent outputs and the spatial range of the native species. RVSs were calculated for two ORSs i.e., both with BRA based ORS ( RVS $\left._{B R A}\right)$ and BRA+CCA based ORS $\left(\mathrm{RVS}_{\mathrm{BRA}+\mathrm{CCA}}\right)$. If a species occurs in more than one river basin, RVSs were calculated separately for each of those basin. Therefore, RVS of species $i$ in basin $a\left(\mathrm{RVS}_{i a}\right)$ was calculated by the following equation;

$$
\mathrm{RVS}_{i a}=\left(\mathrm{ORS}_{a} \times \frac{\mathrm{MB}_{1}+\mathrm{MB}_{2} \cdots \mathrm{MB}_{n i}}{n i}\right) / \log \left(\mathrm{EOO}_{i} \times \mathrm{xP}_{i}\right) \text {; }
$$

Where $\mathrm{MB}_{n i}$ is the mean Maxent value of the micro-basins that contain at least one site-scale record of species $i$ in basin a. $\mathrm{EOO}_{i}$ is the extent of occurrence of species $i$, and $\mathrm{IP}_{i}$ is the number of independent populations of species $i$. The extreme difference between EOO $\times$ IP values of the widespread and localized species was down-weighted by applying a logtransformation. After detecting the outliers (scores outside 1.5 times the interquartile range), we simply considered the mean of the RVSs that were calculated by excluding outliers as the threshold i.e., distinguishing between high and low vulnerability. Finally, we highlighted and proposed the micro-basins that are occupied by a native species with high RVS as the hotspots for potential antagonistic interactions with O. mykiss.

\section{Statistical Analyses}

Differences between mean confidence levels of Basic Risk Assessment (BRA) and Climate Change Assessment (CCA) (in AS-ISK) were tested by permutational analysis of variance (PERANOVA) based on a one-factor design with two levels: BRA and CCA (note that testing of the same differences for the Confidence Factor leads to the same results as the two measures differ only by a constant).

Significant difference among the mean Maxent suitability of the micro-basins of the native species was also tested by PERANOVA based on a one-factor design with 13 levels (all native species) (The dataset for Maxent descriptive data of microbasins and related statistical design is deposited in Supplementary Data sheet 3 ).

PERANOVA was carried out in PERMANOVA+ for PRIMER v6, where we normalized the data and used an Euclidean distance 


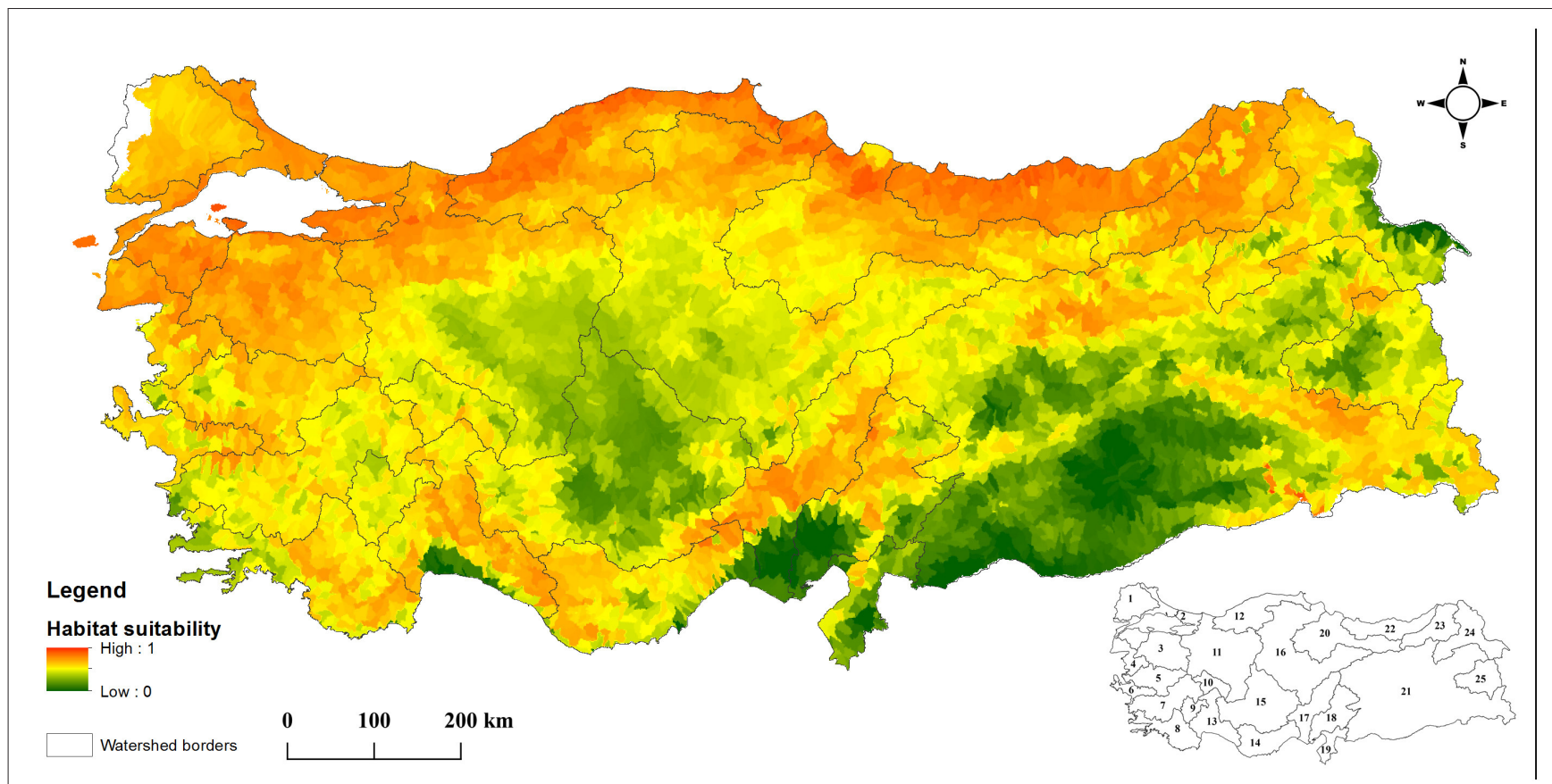

FIGURE 2 | Habitat suitability map of Oncorhynchus mykiss in Turkey. The inset at the bottom-right corner shows the codes for 25 river basins namely 1 , Maritza-Ergene; 2, Marmara; 3, Susurluk; 4, North Aegean; 5, Gediz; 6, Small Menderes; 7, Great Menderes; 8, Western Mediterranean; 9, Burdur; 10, Akarçay; 11 , Sakarya; 12, Western Black Sea; 13, Antalya; 14, Eastern Mediterranean; 15, Konya Closed Basin; 16, Kizilirmak; 17, Seyhan; 18, Ceyhan; 19, Orontes; 20, Yeşilirmak; 21, Euphrates and Tigris; 22, Eastern Black Sea; 23, Çoruh; 24, Kura and Aras; 25, Lake Van Basin.

measure (for BRA-CCA); or square rooted the data and applied a Bray-Curtis dissimilarity measure (for micro-basins). Both analyses ran with 9999 unrestricted permutations of the raw data (Anderson et al., 2008) with statistical effects evaluated at $\alpha=0.05$.

\section{RESULTS}

\section{Habitat Suitability}

The output of the Maxent model for O. mykiss habitat suitability during the calibration phase is given in Figure 1. There is a good concordance between the occurrence data and model outputs and AUC (area under ROC curve) value for training 0.82 , while it was 0.83 for testing (the ROC curve simulation results were depicted in Supplementary Figure 1). Average TSS results for 10 replicate runs was also calculated to be 0.54 . The most significant variables determining the distribution of O. mykiss were average annual minimum temperature (59.5\%), slope (12.2\%) and average annual maximum temperature (9.7\%). Considering the results of the MESS analysis, similarity between the environmental variables of the training dataset and projected dataset was $>0$ for all microbasins, indicating native range data was suitable for modeling the potential distribution of $O$. mykiss in Turkey (see also the map of the MESS analysis in Supplementary Figure 2). Hence, the calibrated model was extended to project the habitat suitability of $O$. mykiss across the river basins in Turkey and the output was given in Figure 2. Given the average Maxent values, the most suitable river basins for O. mykiss

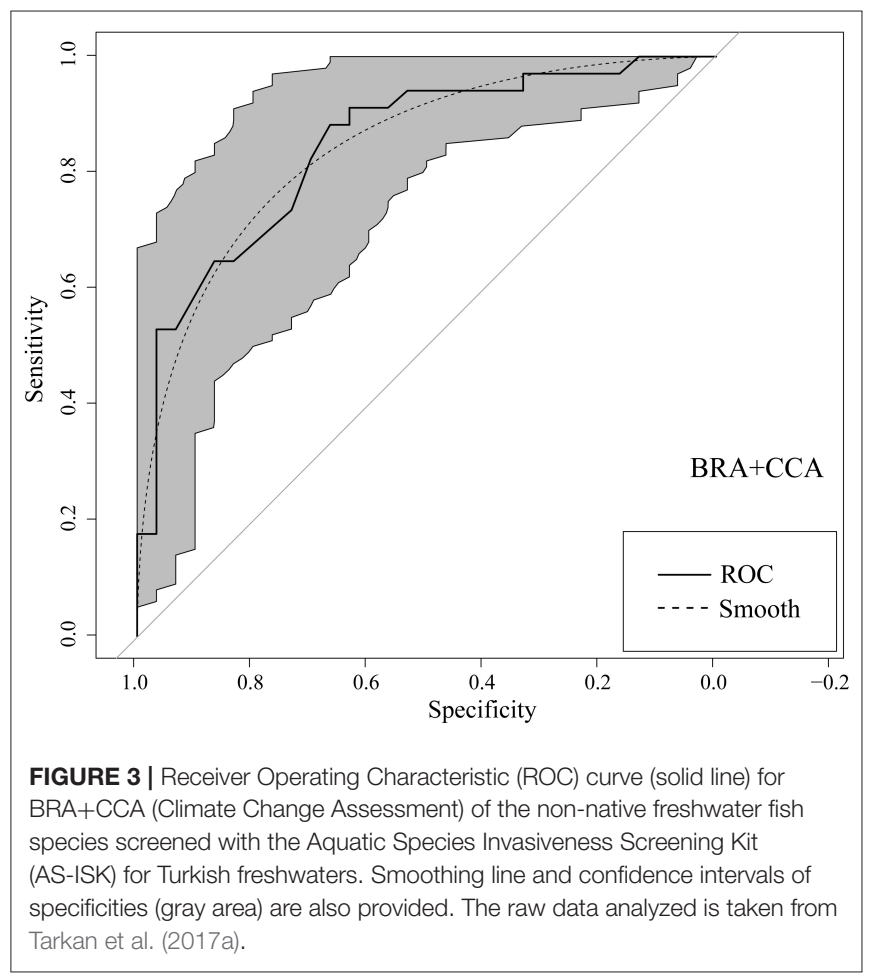

were predicted as the northern basins namely Eastern Black Sea, Western Black Sea and Marmara basins (Figure 2). According to the model, Orontes river basin, Konya-closed 
TABLE 1 | Oncorhynchus mykiss screened with Aquatic Species Invasiveness Screening Kit (AS-ISK) for each of the river basins, i.e., risk assessment (RA) areas, that comprise Turkey, numbered (in [ ]) as per Figure 2.

\begin{tabular}{|c|c|c|c|c|c|c|c|c|c|c|c|}
\hline \multirow[t]{2}{*}{ Basin } & \multicolumn{4}{|c|}{ Assessment component } & \multicolumn{7}{|c|}{ Confidence } \\
\hline & Score & Outcome & Score & Outcome & Delta & Total & BRA & CCA & Total & BRA & CCA \\
\hline Akarçay [10] & 14.0 & Medium & 8.0 & Medium & -6.0 & 2.8 & 2.8 & 2.7 & 0.69 & 0.69 & 0.67 \\
\hline Antalya [13] & 21.0 & Medium & 15.0 & Medium & -6.0 & 2.8 & 2.8 & 2.0 & 0.69 & 0.71 & 0.50 \\
\hline Aras and Kura [24] & 21.0 & Medium & 21.0 & Medium & 0.0 & 2.4 & 2.4 & 2.2 & 0.59 & 0.60 & 0.54 \\
\hline Ceyhan [18] & 18.0 & Medium & 14.0 & Medium & -4.0 & 2.7 & 2.8 & 2.2 & 0.68 & 0.69 & 0.54 \\
\hline Çoruh [23] & 24.0 & Medium & 24.0 & Medium & 0.0 & 2.6 & 2.6 & 3.0 & 0.65 & 0.63 & 0.75 \\
\hline Eastern Black Sea [22] & 28.0 & High & 28.0 & Medium & 0.0 & 2.5 & 2.5 & 3.0 & 0.62 & 0.61 & 0.75 \\
\hline Eastern Mediterranean [14] & 19.0 & Medium & 13.0 & Medium & -6.0 & 2.7 & 2.8 & 2.0 & 0.68 & 0.70 & 0.50 \\
\hline Euphrates and Tigris [21] & 27.5 & Medium & 23.5 & Medium & -4.0 & 2.5 & 2.6 & 2.0 & 0.63 & 0.64 & 0.50 \\
\hline Marmara [2] & 27.0 & Medium & 21.0 & Medium & -6.0 & 2.9 & 3.0 & 2.2 & 0.72 & 0.74 & 0.54 \\
\hline Meriç-Ergene [1] & 28.0 & High & 24.0 & Medium & -4.0 & 2.8 & 2.9 & 2.3 & 0.71 & 0.72 & 0.58 \\
\hline North Aegean [4] & 19.0 & Medium & 19.0 & Medium & 0.0 & 2.9 & 2.9 & 2.5 & 0.72 & 0.73 & 0.63 \\
\hline Orontes [19] & 18.0 & Medium & 14.0 & Medium & -4.0 & 2.7 & 2.8 & 2.2 & 0.68 & 0.70 & 0.54 \\
\hline Sakarya [11] & 24.5 & Medium & 16.5 & Medium & -8.0 & 2.8 & 2.8 & 2.2 & 0.69 & 0.70 & 0.54 \\
\hline Seyhan [17] & 20.0 & Medium & 14.0 & Medium & -6.0 & 2.7 & 2.8 & 2.0 & 0.68 & 0.70 & 0.50 \\
\hline Small Menderes [6] & 13.5 & Medium & 11.5 & Medium & -2.0 & 2.8 & 2.9 & 2.5 & 0.71 & 0.72 & 0.63 \\
\hline Susurluk [3] & 22.5 & Medium & 18.5 & Medium & -4.0 & 2.9 & 2.9 & 2.5 & 0.72 & 0.73 & 0.63 \\
\hline Van [25] & 23.5 & Medium & 19.5 & Medium & -4.0 & 2.5 & 2.5 & 2.0 & 0.62 & 0.63 & 0.50 \\
\hline Western Black Sea [12] & 31.0 & High & 29.0 & Medium & -2.0 & 2.8 & 2.9 & 2.5 & 0.70 & 0.71 & 0.63 \\
\hline
\end{tabular}

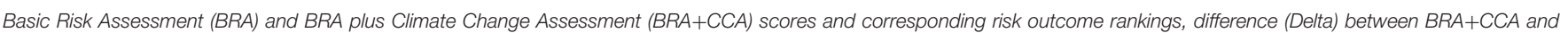

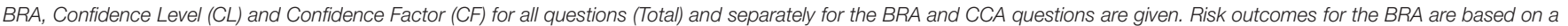
threshold of 27.75 ("Medium" for 1 to 27.75 and "High" for >27.75) and for the BRA+CCA on a threshold of 34.5.

basin and the lower parts of Tigris \& Euphrates basin (the southeast of Turkey) were the least suitable regions for O. mykiss.

\section{AS-ISK}

The receiver operating characteristic curves for the Basic Risk Assessment+ Climate Change Assessment resulted in an AUC of $0.85(0.75-0.9495 \% \mathrm{CI})$ (Figure 3). These AUCs indicated that AS-ISK was able to discriminate between non-invasive and invasive O. mykiss for the assessed basins. Youden's J provided a threshold of 34.5 for the BRA+CCA, which was used for calibration of the AS-ISK risk outcomes. Accordingly, the BRA+CCA threshold allowed to distinguish between medium risk species with scores within [1.0, 34.5[, and high-risk species with scores within $] 34.5,80.0]$. Species classified as low risk were those with BRA+CCA scores within [-32.0, 1.0[ (note the reverse bracket notation indicating in all cases an open interval).

According to the BRA threshold, O. mykiss was classified as "high risk" for $3(12.0 \%)$ of the 25 river basin screened
(Western Black Sea, Eastern Black Sea, and Maritza-Ergene), and as "medium risk" for the remaining ones. The species achieved the highest BRA score in Western Black Sea and lowest BRA score in Small Menderes Basin (31.0 and 13.5, respectively) (Table 1).

The CCA negatively contributed the BRA+CCA scores of $O$. mykiss in $22(88.0 \%)$ of the river basins and resulted in zero contribution for the remaining three, namely Aras-Kura, Çoruh river, and Eastern Black Sea. The largest negative change in score was obtained for Konya-Closed basin $(\Delta=-10)$. Oncorhynchus mykiss was classified as "medium risk" in all of the river basins screened. The highest BRA+CCA score was achieved for the Western Black Sea basin (Table 1).

The CL (over all $55 \mathrm{Qs}$ ) was $2.744 \pm 0.030 \mathrm{SE}$, the $\mathrm{CL}_{\mathrm{BRA}}$ $2.784 \pm 0.030 \mathrm{SE}$, and the $\mathrm{CL}_{\mathrm{CCA}} 2.376 \pm 0.059 \mathrm{SE}$ (hence, in all cases indicating medium to high confidence), and the $\mathrm{CL}_{\mathrm{BRA}}$ was significantly higher than the $\mathrm{CL}_{\mathrm{CCA}}\left(\mathrm{F}_{1.48}^{\#}=37.84\right.$, $P=0.001)$. Similarly, mean values for $\mathrm{CF}=0.683 \pm 0.007 \mathrm{SE}$ and $\mathrm{CF}_{\mathrm{BRA}}=0.692 \pm 0.008 \mathrm{SE}$ were higher than the mean value for the $\mathrm{CF}_{\mathrm{CCA}}=0.593 \pm 0.015 \mathrm{SE}$, and the mean $\mathrm{CF}_{\mathrm{BRA}}$ was 
TABLE 2 | Overall Risk Score (ORS) of the river basins calculated based on their mean Oncorhynchus mykiss habitat suitability values (Maxent) and the Basic Risk Assessment (ORS $\mathrm{ORA}_{\mathrm{A}}$ ) and Climate Change Assessment (ORS $\mathrm{BRA}_{\mathrm{C}} \mathrm{CCA}_{\mathrm{A}}$ ) scores. MB, microbasin.

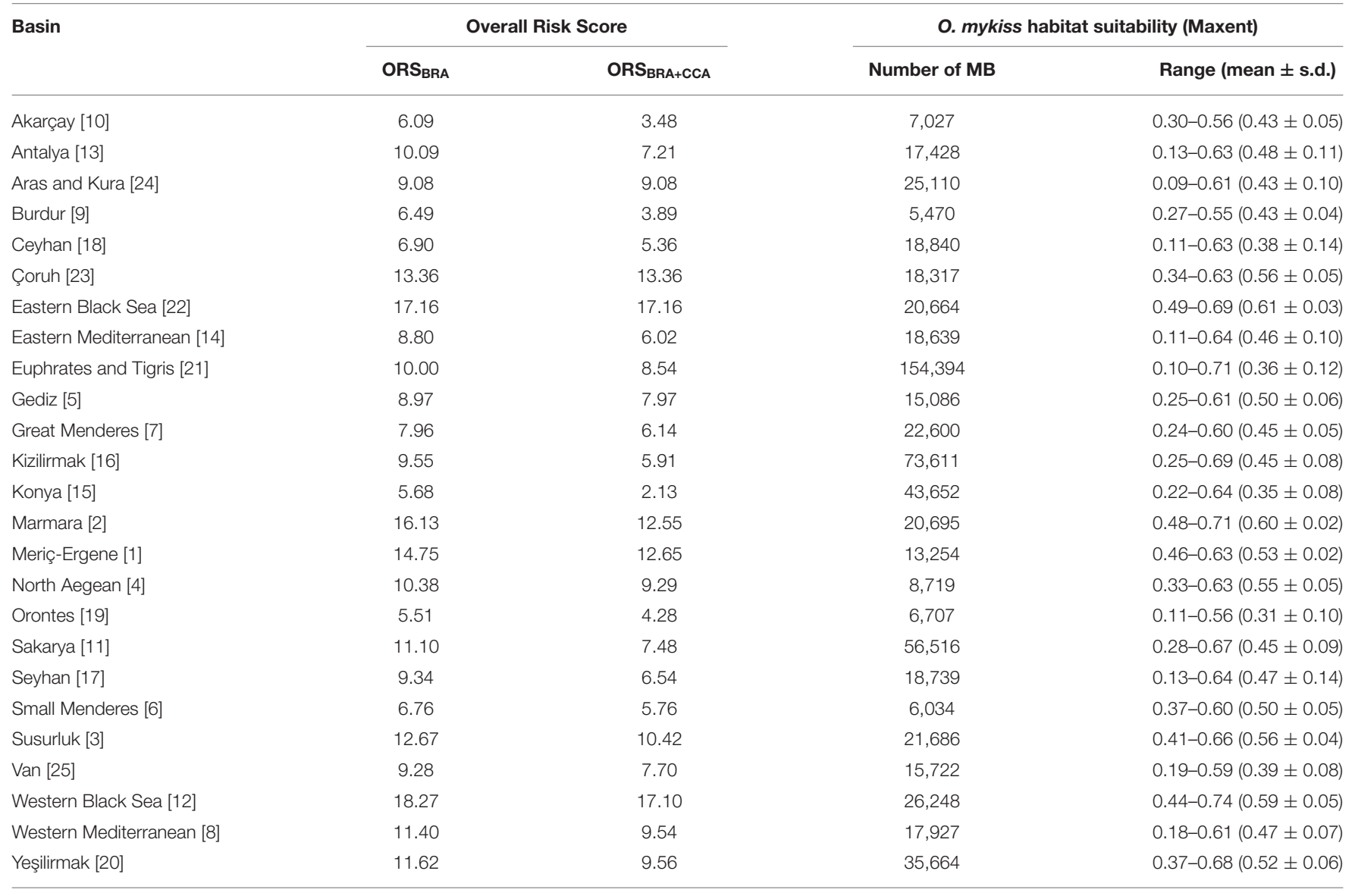

numbers in ([ ] stand for geographic ranges as per Figure 2.

significantly higher than the mean $\mathrm{CF}_{\mathrm{CCA}}$ (same significance values as for the $\mathrm{CL}_{\mathrm{BRA}}$ vs. $\mathrm{CL}_{\mathrm{CCA}}$ comparison due to the two indices being related). In all cases, the narrow standard errors indicated overall similarity in CLs and CFs across the river basins screened. Output reports of AS-ISK analyses of O. mykiss for all river basins are provided in Supplementary Data sheet 1.

\section{Overall Risk Assessment and Its Implications for Native Trout Conservation}

The Overall Risk Score calculated with only basic risk assessment of river basins $\left(\mathrm{ORS}_{\mathrm{BRA}}\right.$ ) ranged from 5.51 to 18.27 (mean 10.29 $\pm 0.70 \mathrm{SE}$ ) for Orontes river basin and the Western Black Sea, respectively. The ORS calculated with basic risk and climate change assessments $\left(\mathrm{ORS}_{\mathrm{BRA}+\mathrm{CCA}}\right)$ ranged from 2.12 to 17.16 (mean $8.36 \pm 0.78 \mathrm{SE}$ ) for Konya-Closed basin and Eastern Black Sea basin, respectively. The ORS $S_{B R A}$ calculated for Aras-Kura, Çoruh river, and Eastern Black Sea were the same with their $\mathrm{ORS}_{\mathrm{BRA}+\mathrm{CCA}}$ due to the zero contribution of the CCA (Table 2).

We identified 13 native trout species whose known distribution range fall entirely (or largely for $S$. coruhensis) within Turkey. The most widespread species, distribute in more than two basins are Salmo coruhensis (15 populations), S. opimus (10 populations), and S. rizeensis (9 populations). The species which are restricted to a single independent lake or stream catchment are S. abanticus, S. chilo, S. fahrettini, S. kottelati, S. munzuricus, S. tigridis, and S. platycephalus. The mean $O$. mykiss habitat suitability of micro-basins that a native species occupies ranged from 0.23 for $S$. opimus (Ceyhan population) to 0.67 for S. rizeensis (Western Black Sea population) (see Table 3); and were significantly different among the species (or populations) examined (Pseudo- $F=7.327 ; P=0.001$; see Supplementary Data sheet $\mathbf{4}$ for the entire outputs of the main and pair-wise tests). The mean of the Relative Vulnerability Scores that were calculated by excluding outlier values were 1.81 for $\mathrm{RVS}_{\mathrm{BRA}}$ and 1.50 for $\mathrm{RVS}_{\mathrm{BRA}+\mathrm{CCA}}$ (Figure 4). The four highest $\mathrm{RVS}_{\mathrm{BRA}}$ and $\mathrm{RVS}_{\mathrm{BRA}+\mathrm{CCA}}$ were detected as the outliers and belonged to Salmo abanticus, S. munzuricus, S. euphrataeus, and S. fahrettini (by descending order). Other populations that ranked as high in terms of both $\mathrm{RVS}_{\mathrm{BRA}}$ and $\mathrm{RVS}_{\mathrm{BRA}+\mathrm{CCA}}$ were S. coruhensis (Eastern Black Sea populations), S. kottelati, S. labecula (Antalya population), S. platycephalus, S. rizeensis (Eastern and Western Black Sea and populations), and S. tigridis (Figure 5; Table 3). Salmo labecula from Seyhan river basin and $S$. chilo ranked as high for RVS BRA $_{\text {, but not for }}$ $\mathrm{RVS}_{\mathrm{BRA}+\mathrm{CCA}}$, suggesting that their vulnerability to O. mykiss will significantly decrease by climate change. $\mathrm{RVS}_{\mathrm{BRA}}$ was also higher 
TABLE 3 | Native salmonid species and populations in Turkey with their Extent of Occurrence (EOO) and total independent population numbers (IP\#).

\begin{tabular}{|c|c|c|c|c|c|c|}
\hline Species & \multicolumn{3}{|c|}{ Spatial analysis } & $\begin{array}{c}\text { O. mykiss suitability of micro-basins } \\
\text { Range (mean } \pm \text { s.d.) }\end{array}$ & \multicolumn{2}{|c|}{ Vulnerability } \\
\hline Salmo chilo & 18 & 89.7 & 1 & $0.44-0.54(0.51 \pm 0.01)$ & 1.81 & 1.41 \\
\hline Salmo coruhensis & 2 & 21225.7 & 15 & $0.57-0.58(0.58 \pm 0.01)$ & 1.22 & 0.82 \\
\hline Salmo coruhensis & 11 & 21225.7 & 15 & $0.56-0.61(0.60 \pm 0.01)$ & 1.70 & 1.32 \\
\hline Salmo coruhensis & 22 & 21225.7 & 15 & $0.55-0.62(0.59 \pm 0.01)$ & 1.82 & 1.82 \\
\hline Salmo coruhensis & 23 & 21225.7 & 15 & $0.41-0.63(0.58 \pm 0.03)$ & 1.41 & 1.41 \\
\hline Salmo euphrataeus & 21 & 8.0 & 1 & $0.41-0.58(0.56 \pm 0.01)$ & 6.22 & 5.31 \\
\hline Salmo fahrettini & 21 & 8.0 & 1 & $0.41-0.51(0.47 \pm 0.01)$ & 5.24 & 4.48 \\
\hline Salmo kottelati & 8 & 46.8 & 1 & $0.44-0.58(0.55 \pm 0.01)$ & 3.73 & 3.13 \\
\hline Salmo labecula & 13 & 215.5 & 2 & $0.50-0.60(0.58 \pm 0.02)$ & 2.22 & 1.59 \\
\hline Salmo opimus & 13 & 488 & 10 & $0.23-0.60(0.49 \pm 0.04)$ & 1.33 & 0.95 \\
\hline Salmo opimus & 14 & 861.5 & 10 & $0.47-0.59(0.53 \pm 0.01)$ & 1.19 & 0.82 \\
\hline Salmo opimus & 18 & 2513.4 & 10 & $0.25-0.61(0.53 \pm 0.03)$ & 0.70 & 0.54 \\
\hline Salmo platycephalus & 17 & 75.8 & 1 & $0.42-0.59(0.55 \pm 0.01)$ & 2.85 & 2.00 \\
\hline Salmo rizeensis & 12 & 5132.9 & 9 & $0.58-0.67(0.65 \pm 0.01)$ & 2.54 & 2.37 \\
\hline Salmo rizeensis & 20 & 5132.9 & 9 & $0.43-0.60(0.52 \pm 0.01)$ & 1.30 & 1.07 \\
\hline Salmo rizeensis & 22 & 5132.9 & 9 & $0.58-0.62(0.61 \pm 0.00)$ & 2.24 & 2.24 \\
\hline Salmo rizeensis & 23 & 5132.9 & 9 & $0.52-0.61(0.56 \pm 0.01)$ & 1.61 & 1.61 \\
\hline Salmo tigridis & 21 & 135.7 & 2 & $0.50-0.59(0.58 \pm 0.01)$ & 2.37 & 2.02 \\
\hline
\end{tabular}

Basin codes stand for the basins per Figure 2. RVS $S_{B R A+C C A}$ and $R V S_{B R A}$ are the relative vulnerability scores calculated from ORS $B R A+C C A$ and ORS $B R A$ respectively. Numbers in bold stand for high vulnerability (RVSs over thresholds).

than $\mathrm{RVS}_{\mathrm{BRA}+\mathrm{CCA}}$ for all species except the Çoruh and Eastern Black Sea populations of S. coruhensis and S. rizeensis (Table 3). The known distribution ranges of the species (populations) with high $\mathrm{RVS}_{\mathrm{BRA}}$ and $\mathrm{RVS}_{\mathrm{BRA}+\mathrm{CCA}}$ are proposed as the hotspots for potential overlap and interaction with O. mykiss (Figure 6). The site descriptions of hotspots were provided in Table 4. All the occurrence records of O. mykiss escapes compiled from literature and the occurrence dataset is provided in the Supplementary Table 1 . The river tributaries where possess at least one site-scale record of $O$. mykiss were highlighted. These river patches located on the moderate to high dark areas indicate a reasonable accuracy of the potential map (Figure 6). According to the occurrence map, S. tigridis, S. kottelati and populations of $S$. coruhensis and S. rizeensis in the Eastern Black Sea Basin and $S$. labecula in Seyhan river basin seem to already exposed to escapees of O. mykiss.

\section{DISCUSSION}

\section{Establishment and Invasiveness Potential of Oncorhynchus mykiss}

As a risk screening (or identification) and decision support tool, AS-ISK inherently makes use of expert opinion to respond the assessment questions. There has been a debate on whether the climate change assessment of AS-ISK is subjective as it allows the use of Köppen-Geiger climate types, thus resulting in the qualitative evaluation for climate matching (Marcot et al., 2019). However, AS-ISK also primarily recommends to benefit from a climate-matching approach (e.g., Climex, GARP, Climatch) or physiological tolerances of species in question (Copp et al., 2016a; Hill et al., 2020). To this end, we developed an alternative way to the risk assessment by integrating ASISK with the outputs of a species distribution model (Maxent), which potentially reflects both environmental (including current climate) matching and physiological tolerance. In the present study, Maxent results constituted the quantitative base for the establishment potential of $O$. mykiss in Turkey. However, our ensemble approach can be applied in various ways such as the addition of different climatic scenarios (future climate) into the establishment potential component, that can, in turn improve the Climate Change Assessment part of the AS-ISK. For risk screening, using Maxent to predict the potential distribution of an invasive species is a powerful method (Bosso et al., 2017; Rodríguez-Merino et al., 2018) yet it has been inadequate in utilizing such inputs as the potential impacts, introduction pathways, successful introduction events or biogeographical and historical traits of the taxon. AS-ISK mitigates these gaps by its related query sections. For example, in the present study 


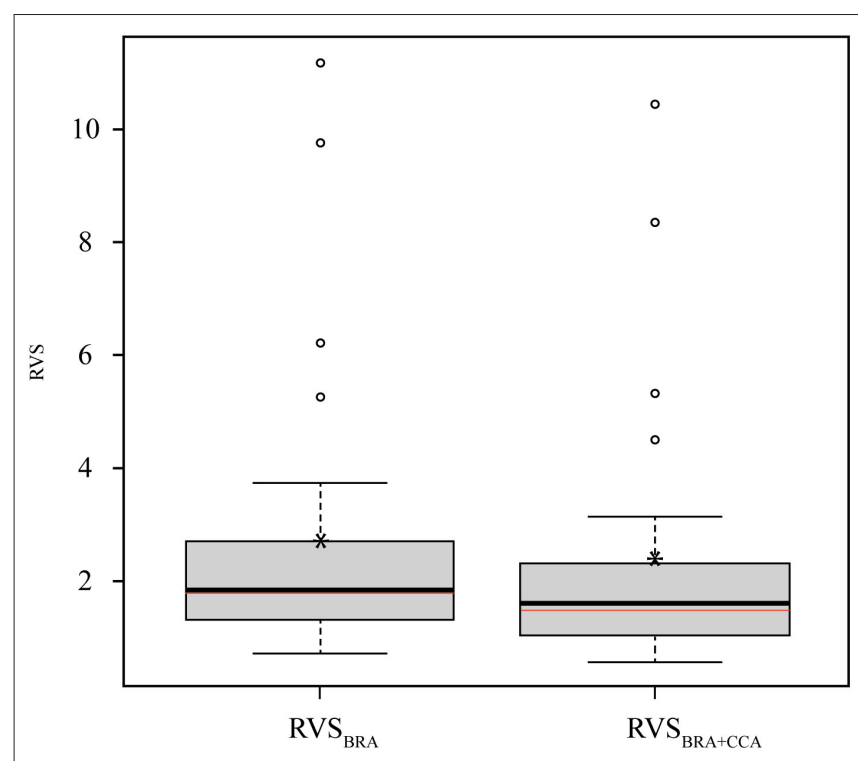

FIGURE 4 | Box-whisker plot representation of the Relative Vulnerability Scores (RVS) of native salmonid species and populations in Turkey. RVSs were calculated for two kinds of overall risk score (ORS), i.e., Basic Risk Assessment (BRA)-based ORS (RVS BRA $_{\text {) }}$ and Climate Change Assessment (CCA)-based ORS (RVS $\mathrm{BRA}+\mathrm{CCA})$. Boxes extend from the 25th to the 75th percentile of each RVS's distribution of values; whiskers above and below the box indicate the 90th and 10th percentiles, respectively. Circles indicate the outliers (scores outside 1.5 times the interquartile range). horizontal black lines within the boxes denote median, asterisks denote the mean of the values. Horizontal red lines within the boxes denote the mean RVSs calculated by excluding the outliers.

Marmara, Susurluk and North Aegean basins ranked high for their Maxent values, whereas AS-ISK scores substantially decreased their ranks, suggesting that O. mykiss is likely to survive in these basins but less likely to become invasive. Therefore, Overall Risk Score has the potential to balance between these two main components by combining the probability and impact.

One of the most frequently used spatial scales on which species' invasiveness potential is screened is the country-level (Perdikaris et al., 2016; Tarkan et al., 2017a; Uyan et al., 2020; Zieba et al., 2020), however, using national boundaries for risk screening of taxa whose distribution is strongly related to climatic conditions (like Salmonids) may result in rough estimates, if the country covers great climatic and geographical heterogeneity. As for risk screening of $O$. mykiss in Turkey, where several different climate types and a diverse topography are found (Deniz et al., 2011; Iyigun et al., 2013), use of an alternative spatial scale than the country-level is needed. Selecting the river basins as a spatial scale in this regard is more appropriate, as they are compact and coherent hydrological units that also reflect biogeographical and ecological boundaries to a certain extent. This can also enable assessors to predict certain cases (e.g., species distributions and traits) more precisely (e.g., Dodd et al., 2019) than considering the whole country level. Still, increasing resolution of assessments by decreasing spatial scale of risk assessment area would enhance the predictions for the establishment and invasiveness likelihood of salmonid species since they frequently show local adaptation to each environment. For instance, in a country-level basin screening O. mykiss yielded 20 in both its BRA and BRA+CAA which resulted it in being categorized as medium risk potential of being invasive in Turkey (Tarkan et al., 2017a). However, our river basin screenings resulted in high potential risk for three basins, which suggest that coarser scale RA selections may mask true invasiveness potential, at least in cases of geographically heterogenous RAs such as Turkey.

Oncorhynchus mykiss is a cold-water species native to the Pacific drainages of North America and northeastern Siberia (Behnke, 1979). It is therefore not surprising that the most explanatory variables determining the distribution of $O$. mykiss was the average annual minimum and maximum temperature (ca 70\% in the present study) (Clark et al., 2001; Coleman and Fausch, 2007). This might largely explain why the northern river basins are found to be more suitable for O. mykiss compared to those warmer regions located in central and southern Turkey. This was also clearly reflected by the CCA (Climate Change Assessment) scores, which resulted in a negative contribution for $O$. mykiss in most assessed basins under predicted climate warming conditions (Table 1). However, there are still some river basins with no change in CCA scores suggesting habitat suitability of $O$. mykiss will not be affected in the short term by means of climatic variables. Although BRA +CCA is significantly lower than BRA (Basic Risk Assessment) due to the intrinsically higher level of uncertainty in future climate change projections (Killi et al., 2020, Uyan et al., 2020), this is supported by the high confidence ranking of CCA reflecting both extensive literature information available on the screened species and the similar level of expertise amongst assessors, hence increasing the reliability of the screening outcomes.

Some other factors such as flow regime (Fausch et al., 2001), stream size (Rahel and Nibbelink, 1999), and gradient (Adams, 1999) have been shown to affect distribution and establishment of O. mykiss. In the present study, slope was the second most important defining variable that might explain higher habitat suitability for northern RAs. This could be attributed to the occurrence of steep and fast-flowing streams in Black Sea region (northern part of Anatolia) that could have contributed the species' persistence (e.g., Fausch et al., 2001). However, the low invasiveness potential of $O$. mykiss was attributed to the poor persistence of rainbow trout populations to be locally established, mainly due to biotic resistance from competition, predation and parasites or diseases (Fausch, 2007). Angling and wild collecting as other crucial factors hamper invasion success of O. mykiss in the U.K (Fausch, 2007), and these cannot be ruled out for Turkey.

\section{Priority and Conservation of Native Salmonids}

The diversity of trout species in Western Palearctic has long been a subject of dispute among taxonomists. Salmo trutta had been considered a widespread polymorphic species that distributed throughout Europe reaching southwards to the Atlas Range (Morocco, Algeria) and eastwards to the upper Amu-Darya drainage in Afghanistan (Kottelat, 1997). In recent decades, large 


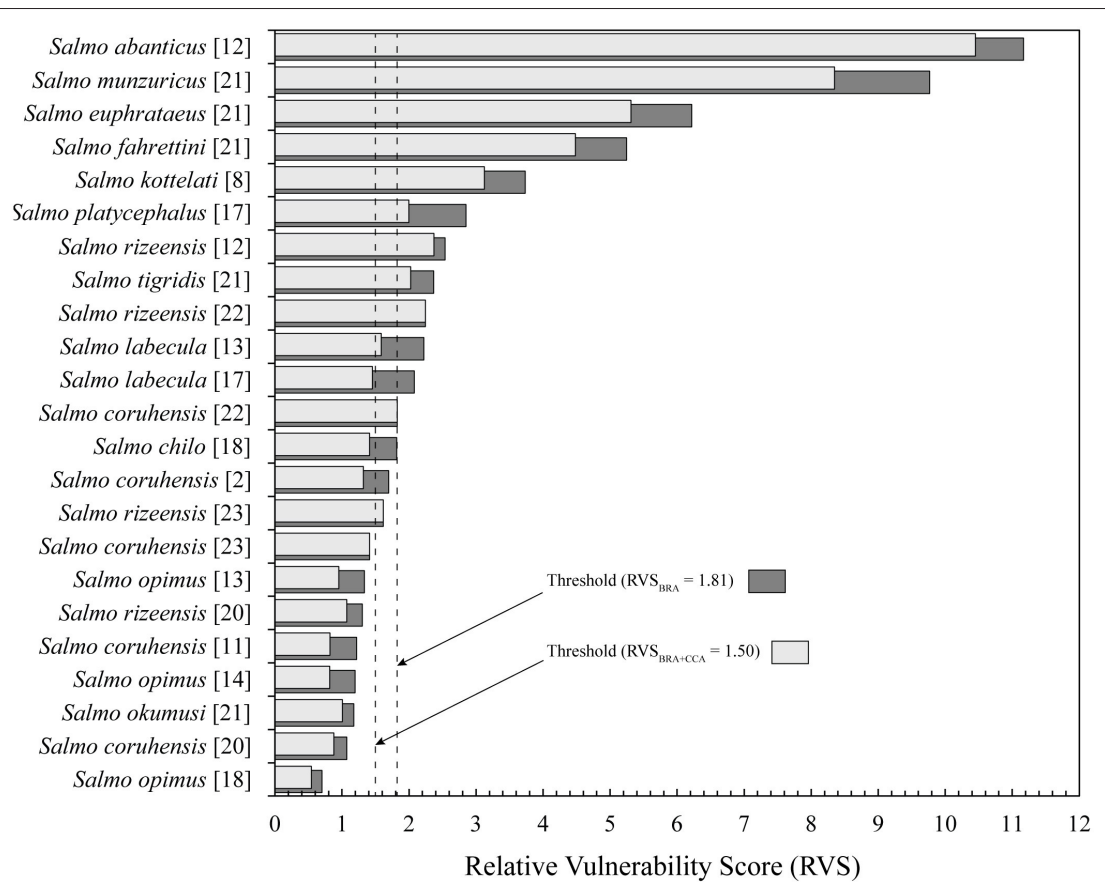

FIGURE 5 | Relative Vulnerability Scores (RVS) of native Salmo species and populations in Turkey. Brackets ([ ]) after species (or populations) present river basin codes are as per Figure 2.

numbers of studies have uncovered the diversity of trout in Europe by the recognition of several species that had been earlier identified as morphs or ecotypes of S. trutta (Delling, 2003, 2011; Delling and Doadrio, 2005). The case for the Turkish trout species has followed similar path. Only five species of trout had been recognized up to 2010 (S. abanticus, S. caspius, S. labrax, S. macrostigma, and $S$. platycephalus). In the last decade, 11 additional species have been described from Turkey, as well as the existence of S. labrax and S. macrostigma in Turkey was disproven by extensive molecular and morphological studies (Turan et al., 2010, 2011, 2012, 2014a,b, 2017, 2020). Although the number of trout species in Turkey is still tentative, and some have been questioned for their validity (Kalayci et al., 2018; Ninua et al., 2018), here we follow in-state taxonomy. In the light of the Aichi Biodiversity Targets, agreed in 2010 (https://www.cbd. int/sp/targets/), biodiversity has been recognized not only at the ecosystem and species level, but also at the genetic diversity level. Thereof, regardless of whether the current trout taxonomy is established or not, we consider the geographically and/or genetically distinct native trout populations as conservation and management units.

Before the present study, the number of species or populations of trout that have been directly exposed to O. mykiss in nature was poorly documented and anecdotal in Turkey. The present research, has demonstrated, for the first time, to what extent the spatial overlap currently exists between O. mykiss and native salmonids, and how this might change in the future. On one hand, stocking of non-native salmonids for aquaculture and recreational fishing, and escapement from these systems into nature, is an important issue in salmonid conservation.
Several studies have documented negative impacts of escapee non-native salmonids, mainly $O$. mykiss and the brown trout (Salmo trutta), on native salmonids, with the latter not being a farmed species in Turkey (for a detailed account, see Fausch, 2007; Stanković et al., 2015; Hasegawa, 2020). Among the pronounced impacts, displacement of native salmonids by nonnatives through reduced fitness and survival (Muhlfeld et al., 2009; Houde et al., 2015), competitive exclusion (Fausch, 1988; Seiler and Keeley, 2009), hybridization (Weigel et al., 2003; Boyer et al., 2008) or predation (Budy and Gaeta, 2018) have been well-studied in many parts of the world, especially in the North America, Europe, New Zealand and Japan, yet none of these impacts have been documented in Turkey. On the other hand, interpopulation introductions of native salmonids for wild stock enhancements is another conservation issue, as mixing species is always problematic. In Turkey, such an effort has been made to support wild populations of salmonids, especially S. rizeensis, S. coruhensis and S. abanticus (Akkan et al., 2016), and much more care is needed to avoid mixing the populations of different species and the mismatching of species to their native ranges during introductions.

According to our proposed relative vulnerability measure, $S$. abanticus received the highest score, suggesting that the species is represented by a low number of independent populations (IP $=1$ ) in a restricted area with relatively a higher potential than other native salmonids to be exposed to O. mykiss. Among the native trout species with the five highest Relative Vulnerability Scores, only S. abanticus has an IUCN Red List category (VU, Freyhof, 2019a), whereas the others have not been evaluated. This calls for an urgent need to specify their conservation status. The 


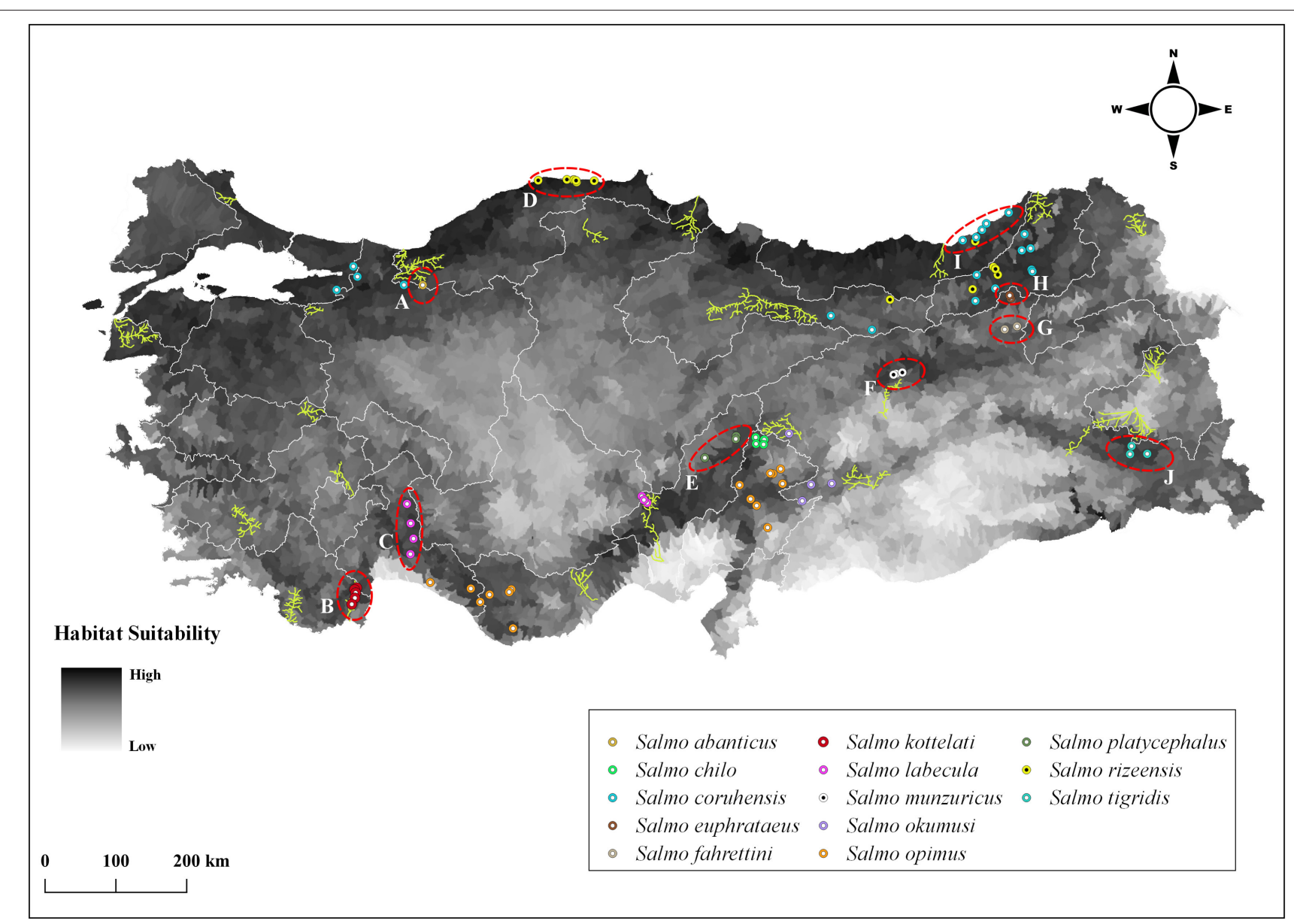

FIGURE 6 | The distribution of native Salmo species and the range of Oncorhynchus mykiss farm escapes in Turkey. The colored circles represent site scale records per native species; the river network patches (in yellow) represent the tributaries where O. mykiss farm escapements have been recorded. The map is black-white equivalent of Figure 2 (i.e., habitat suitability map of $O$. mykiss). The red-dashed circles denote proposed hotspot areas, and are also coded by letters. The coordinates and sources from which O. mykiss escape records taken were provided in Supplementary Table 1.

TABLE 4 | Description and geographic ranges of hotspots proposed for species and populations of native Salmo spp. in Turkey. Map codes correspond to the red circles depicted in Figure 6.

\begin{tabular}{|c|c|c|c|c|c|}
\hline $\begin{array}{l}\text { Map } \\
\text { Code }\end{array}$ & Species & Basin & Hotspot description & $\begin{array}{l}\text { Latitude } \\
\text { range }\end{array}$ & $\begin{array}{l}\text { Longitude } \\
\text { range }\end{array}$ \\
\hline A & S. abanticus & Western Black Sea & Lake Abant drainage nearly $30 \mathrm{~km}$ southwest of Bolu & $40.53-40.81$ & $31.19-31.65$ \\
\hline B & S. kottelati & $\begin{array}{l}\text { Western } \\
\text { Mediterranean }\end{array}$ & $\begin{array}{l}\text { Alakir river drainage between the eastern Beydaglari mountain range and the western Gulf } \\
\text { of Antalya. The area from Alakir reservoir to the headwaters is of great importance }\end{array}$ & $36.31-36.86$ & $30.10-30.27$ \\
\hline C & S. labecula & Antalya & $\begin{array}{l}\text { Köprüçay River drainage between the western Taurus Mountain range around Sütçüler } \\
\text { (Isparta) and south of the Köprülü Canyon National Park (Antalya) }\end{array}$ & $37.12-37.94$ & $30.94-31.40$ \\
\hline D & S. rizeensis & Western Black Sea & $\begin{array}{l}\text { Small coastal streams from the west (Cide-Devrekani) to the east of (Çatalzeytin) } \\
\text { Kastamonu }\end{array}$ & $41.76-42.01$ & $33.32-34.25$ \\
\hline $\mathrm{E}$ & S. platycephalus & Seyhan & Zamanti River between Pinarbaşi and Kizlarsekisi in the upper Seyhan River drainage. & $37.56-38.78$ & $35.55-36.56$ \\
\hline $\mathrm{F}$ & S. munzuricus & Euphrates and Tigris & $\begin{array}{l}\text { Munzur river (upper Euphrates) from the Gözeler springs (headwaters of the river) to the } \\
\text { north of Tunceli province. }\end{array}$ & $39.19-39.52$ & $38.77-39.68$ \\
\hline G & S. fahrettini & Euphrates and Tigris & $\begin{array}{l}\text { Headwaters of Karasu river in the upper Euphrates. Streams Tekke and Ömertepesuyu in } \\
\text { west of Palandöken Montain (Erzurum) }\end{array}$ & $39.71-39.98$ & $40.84-41.25$ \\
\hline $\mathrm{H}$ & S. euphrataeus & Euphrates and Tigris & $\begin{array}{l}\text { Streams Kuzgun, Senyurt and llica around Kuzgun Dam Lake in Karasu river drainage } \\
\text { (upper Euphrates), about } 35 \mathrm{~km} \text { northeast of Erzurum. }\end{array}$ & $39.91-40.35$ & $40.75-41.27$ \\
\hline I & $\begin{array}{l}\text { S. rizeensis and } \\
\text { S. coruhensis }\end{array}$ & Eastern Black Sea & Coastal streams between Hopa (Artvin) and lyidere (Rize) in the eastern Black Sea region. & $40.82-41.27$ & $40.33-41.45$ \\
\hline J & S. tigridis & Euphrates and Tigris & $\begin{array}{l}\text { Two headwaters of Botan River (uppermost Tigris drainage). Stream Müküs at Bahçesaray } \\
\text { and Çatak River at Çatak (Van) }\end{array}$ & $37.98-38.24$ & $42.65-43.35$ \\
\hline
\end{tabular}


RVS alone reflects the relative vulnerability of the examined trout species to the interaction potential with O. mykiss. Therefore, this metric can be considered as a complementary tool to improve conservation assessments (e.g., IUCN Red list assessment), though it can help to propose relative priority for a range of species (or populations) examined, when applied solely. In this context, our tentative attempt, in which we determine the threshold can be modified by any case-specific conditions, such as, for example, considering RVS of certain species (or populations) that is known to have a virtual interaction (reported hybridization or competition) with O. mykiss as the threshold or reference point.

As reviewed and suggested by Coates et al. (2018), infraspecific entities have always been problematic for evolutionary and conservation biologists in deciding conservation units. However, it is widely recommended that distinct populations within a species would be better accepted and treated as distinct genetic lineages for the practical assessment of conservation status or impact assessments (Frankham et al., 2012; Taylor et al., 2017; Coates et al., 2018). In agreement with this conservative approach, although S. rizeensis (LC) and S. coruhensis (NT) are relatively wide-spread, some of their populations received high RVS as their distribution ranges overlap with habitats suitable to O. mykiss. Conversely, all populations of S. opimus from southern drainages have been represented by relatively low RVS, although the species is classified as Endangered by the IUCN (Freyhof, 2019b). This result could be attributed to the potential failure of $O$. mykiss in southern basins (Table 2). This potential is expected to increase for this spatial range by the predicted climate change. In parallel with this assumption, $\mathrm{RVS}_{\mathrm{BRA}+\mathrm{CCA}}$ of $S$. labecula population from Antalya and S. chilo from Ceyhan remained under the proposed threshold, even though their RVS $_{\text {BRA }}$ was above the corresponding threshold.

\section{CONCLUDING REMARKS}

Whilst the use of non-native species has an indispensable importance for international aquaculture, it also poses considerably high risks to native biodiversity, as escaped aquatic species may become invasive in certain environments. Despite the fact that preventing organisms from escaping is the best interest of aquaculturists - who engage in the farming of fish, mollusks, crustaceans and aquatic plants-, it is widely known that species in fact do escape. This is not only true for fish species, as is the case in the present study, but also for some mammals (American minks, Anderson and Valenzuela, 2011; Nutria, Simberloff, 2011), marine shellfish (Galil, 2011), garden plants (Reichard and White, 2001) and aquatic plants, as the most popular example being the killer algae, Caulerpa toxifolia (Meinesz and Hesse, 1991), all of which could have been successfully introduced to many parts of the World.

As for future prospects, it is crucial that we incorporate escape probability from the farms to better quantify the overall risk exposed by $O$. mykiss. Fish escapes from farms can be both detrimental to the natural species and can also reduce income of fish farms. For this aim, we highly anticipate receiving the benefit of aquaculture-specific and post-screening risk analysis tools such as European Non-native Species in Aquaculture Risk Analysis Scheme (ENSARS) (Copp et al., 2016b; Tarkan et al., 2020), by also implementing the information on farm intensity (number of fish farms per unit area) and farm capacity. Fish escape should also be taken seriously especially for the hotspots we proposed, and related measures should be amended to prevent or minimize it. According to the confirmed escape records, several species and populations of native trouts have already been exposed to escapees of $O$. mykiss, and we propose to give priority to monitor those species or populations in near future.

There is still ongoing debate as to whether species distribution models are accurate enough to predict potential establishment and spread of introduced species (Bertolino et al., 2020). Therefore, collecting field data would be needed to support the validation of our modeling. Considerable gaps in the knowledge have been identified in both the science and policy for the effective management of biological invasions, which indicate that non-native species are not properly managed because they receive less attention from a wide range of related groups (i.e., scientists, policy-makers, and managers). This is substantially important in tackling invasive non-native species through prevention, early detection, rapid response, eradication and control, which are all considered to be financially demanding (Britton et al., 2011). In cases where river basins contain both native trout species and $O$. mykiss, implementation of such measures significantly depend on the local authorities and public perception mainly because of the economic value of O. mykiss. However, as the results of the present study suggest a potential impact on native and endemic trout species, a balance should be found between the ecological impacts and the economic benefits of O. mykiss.

\section{DATA AVAILABILITY STATEMENT}

The original contributions presented in the study are included in the article/Supplementary Material, further inquiries can be directed to the corresponding author.

\section{ETHICS STATEMENT}

Ethical review and approval was not required for the animal study because the study has based on the methodology that includes the risk screening and spatial modeling approaches. No animals were used.

\section{AUTHOR CONTRIBUTIONS}

BY and AST conceived and designed the study, employed risk screening of the river basins, interpreted results, and drafted the manuscript. TB performed Maxent modeling, interpreted results, and revised the manuscript. FGE conceived and designed the study, interpreted results, and revised the manuscript. CK conceived and designed the study, employed risk screening of the river basins, and developed native salmonid occurrence dataset. 
All authors contributed to the paper, read, and approved the final version of the manuscript.

\section{ACKNOWLEDGMENTS}

We would like to thank Prof. Mehmet Ekmekçi (Ankara) and Başak Bahtiyar (Ankara) for their valuable comments on the first ideas. We thank Dr. Mustafa Durmuş (Ankara) for his

\section{REFERENCES}

Adams, S. B. (1999). Mechanisms Limiting a Vertebrate Invasion: Brook Trout in Mountain Streams of the Northwestern USA. Doctoral Dissertation, University of Montana, Missoula, MT, United States.

Akçakaya, H. R., and Root, W. (2007). RAMAS ${ }^{\circledR}$ Red List Professional: Spatial and Temporal Data Analysis for Threatened Species Classifications Under Uncertainty. Setauket, NY: Applied Biomathematics.

Akkan, Ö., Başçinar, N., and Bulut, N., Ümüzer, A. (2016). Brown trout production, and fish releasing in inland waters at forest areas under the project monitoring and control: Artvin - Yusufeli study. J. Anatol. Environ. Animal Sci. 3, 83-86. doi: 10.35229/jaes.280745

Allouche, O., Tsoar, A., and Kadmon, R. (2006). Assessing the accuracy of species distribution models: prevalence, kappa and the true skill statistic (TSS). J. Appl. Ecol. 43, 1223-1232. doi: 10.1111/j.1365-2664.2006.01214.x

Anderson, C. B., and Valenzuela, J. A. (2011). "Mammals, aquatic," in Encyclopedia of Biological Invasions, eds D. Simberloff, and M. Rejmánek (Berkeley and Los Angeles, CA: University of California Press), 379- 385.

Anderson, M. J., Gorley, R. N., and Clarke, K. R. (2008). PERMANOVA forPRIMER: guide to software and statistical methods. Plymouth: PRIMERELtd.

Banerjee, A., K., Mukherjee, A., Guo W, Liu, Y., and Huang, Y. (2019). Spatiotemporal patterns of climatic niche dynamics of an invasive plant Mikania micrantha Kunth and its potential distribution under projected climate change. Front. Ecol. Evol. 7:291. doi: 10.3389/fevo.2019.00291

Behnke, R. J. (1979). Monograph of the Native Trouts of the Genus Salmo of Western North America. Lakewood, CO: U.S. Forest Service, Region 2. doi: 10.5962/bhl.title.110986

Bertolino, S., Sciandra, C., Bosso, L., Danilo, R., Lurz, P. W. W., and Febbraro, M. (2020). Spatially explicit models as tools for implementing effective management strategies for invasive alien mammals. Mammal Rev. 50, 187-199. doi: 10.1111/mam.12185

Bewick, V., Cheek, L., and Ball, J. (2004). Statistics review 13: receiver operating characteristic curves. Crit. Care 8, 508-512. doi: 10.1186/cc3000

Bosso, L., De Conno, C., and Russo, D. (2017). Modelling the risk posed by the zebra mussel dreissena polymorpha: Italy as a case study. Environ. Manage. 60, 304-313. doi: 10.1007/s00267-017-0882-8

Boyer, M. C., Muhlfeld, C. C., and Allendorf, F. W. (2008). Rainbow trout (Oncorhynchus mykiss) invasion and the spread of hybridization with native westslope cutthroat trout (Oncorhynchus clarkii lewisi). Can. J. Fish. Aquat. Sci. 65:658669. doi: 10.1139/f08-001

Britton, J. R., Gozlan, R. E., and Copp, G. H. (2011). Managing non-native fish in the environment. Fish Fish 12, 256-274. doi: 10.1111/j.1467-2979.2010. 00390.x

Brooks, K. M., Stierns, A. R., Mahnken, C. V., and Blackburn, D. B. (2003). Chemical and biological remediation of the Benthos near Atlantic Salmon farms. Aquaculture 219, 355-377. doi: 10.1016/S0044-8486(02) 00528-8

Budy, P., and Gaeta, J. W. (2018). "Brown trout as an invader: a synthesis of problems and perspectives in North America," in Brown Trout: Biology, Ecology and Management, eds J. Lobón-Cerviá, and N. Sanz (Chichester: John Wiley and Sons Ltd), 525-543. doi: 10.1002/9781119268352.ch20

Casal, C. M. V. (2006). Global documentation of fish introductions: the growing crisis and recommendations for action. Biol. Invasions 8, 3-11. doi: $10.1007 / \mathrm{s} 10530-005-0231-3$ contribution in ideas and GIS applications. We also thank Julian Johnson (Ankara) for improving the language of the manuscript.

\section{SUPPLEMENTARY MATERIAL}

The Supplementary Material for this article can be found online at: https://www.frontiersin.org/articles/10.3389/fevo. 2020.599881/full\#supplementary-material

Charles, H., and Dukes, J. S. (2008). "Impacts of invasive species on ecosystem services," in Biological Invasions. Ecological Studies (Analysis and Synthesis), Vol 193, ed W. Nentwig (Berlin, Heidelberg: Springer), 217-237.

Clark, M. E., Rose, K. A., Levine, D. A., and Hargrove, W. W. (2001). Predicting climate change effects on Appalachian trout: combining GIS and individual-based modeling. Ecol. Appl. 11, 161-178. doi: 10.1890/10510761(2001)011[0161:PCCEOA]2.0.CO;2

Coates, D. J., Byrne, M., and Moritz, C. (2018). Genetic diversity and conservation units: dealing with the species-population continuum in the age of genomics. Front. Ecol. Evol. 6:165. doi: 10.3389/fevo.2018.00165

Coleman, M. A., and Fausch, K. D. (2007). Cold summer temperature limits recruitment of age- 0 cutthroat trout in high-elevation Colorado streams. Trans. Am. Fish. Soc. 136, 1231-1244. doi: 10.1577/T05-244.1

Copp, G. H., Bianco, P. G., Bogutskaya, N., Eros, T., Falka, I., Ferreira, M. T., et al. (2005a). To be, or not to be, a non-native freshwater fish? J. Appl. Ichthyol. 21, 242-262. doi: 10.1111/j.1439-0426.2005.00690.x

Copp, G. H., Garthwaite, R., and Gozlan, R. E. (2005b). Risk identification and assessment of non-native freshwater fishes: a summary of concepts and perspectives on protocols for the UK. J. Appl. Ichthyol. 21, 371-373. doi: 10.1111/j.1439-0426.2005.00692.x

Copp, G. H., Russell, I. C., Peeler, E. J., Gherardi, F., Tricarico, E., Macleod, A., et al. (2016b). European Non-native Species in Aquaculture Risk Analysis Scheme a summary of assessment protocols and decision support tools for use of alien species in aquaculture. Fish. Manag. Ecol. 23, 1-11. doi: 10.1111/fme.12074

Copp, G. H., Vilizzi, L., Tidbury, H., Stebbing, P. D., Tarkan, A. S., Moissec, L., and Goulletquer, P.h. (2016a). Development of a generic decision-support tool for identifying potentially invasive aquatic taxa: AS-ISK. Manag. Biol. Invas. 7, 343-350. doi: 10.3391/mbi.2016.7.4.04

Crawford, S. S., and Muir, A. M. (2008). Global introductions of salmon and trout in the genus Oncorhynchus: 1870-2007. Rev. Fish Biol. Fish. 18, 313-344. doi: 10.1007/s11160-007-9079-1

Cromey, C. J., Nickell, T. D., Black, K. D., Provost, P. G., and Griffiths, C. R. (2002). Validation of a fish farm waste resuspension model by use of a particulate tracer discharged from a point source in a coastal environment. Estuaries Coast 25, 916-929. doi: 10.1007/BF02691340

Delling, B. (2003). Species Diversity and Phylogeny of Salmo with Emphasis on Southern Trouts (Teleostei, Salmonidae). Thesis, Stockholm University, Stockholm, Sweden.

Delling, B. (2011). Diversity of western and southern Balkan trouts, with the description of a new species from the Louros River, Greece (Teleostei: Salmonidae). Ichthyol. Explor. Freshw. 21, 331-344.

Delling, B., and Doadrio, I. (2005). Systematics of the trouts endemic to Moroccan lakes, with description of a new species (Teleostei: Salmonidae). Ichthyol. Explor. Freshw. 16, 49-64.

Demir, N., Kirkagaç, M. U., Pulatsü S., and Bekcan, S. (2001). Influence of trout cage culture on water quality, plankton and benthos anatolian dam lake. Isr J Aquac. $53,115-127$.

Deniz, A., Toros, H., and Incecik, S. (2011). Spatial variations of climate indices in Turkey. Int. J. Climatol. 31, 394-403. doi: 10.1002/joc.2081

Dodd, J. A., Vilizzi, L., Bean, C. W., Davison, P. I., and Copp, G. H. (2019). At what spatial scale should risk screenings of translocated freshwater fishes be undertaken - river basin district or climo-geographic designation? Biol. Conserv. 230, 122-130. doi: 10.1016/j.biocon.2018.12.002

Elith, J., Kearney, M., and Phillips, S. (2010). The art of modelling range-shifting species. Methods Ecol. Evol. 1, 330-342. doi: 10.1111/j.2041-210X.2010.00036.x 
Ertürk-Gürkan, S., and Yalçin Özdilek, S. (2019). The effects of trout culture on diet and food availability of native freshwater fish populations. Aquac. Res. 50, 1212-1219. doi: 10.1111/are.13995

Essl, F., Bacher, S., Blackburn, T. M., Booy, O., Brundu, G., Brunel, S., et al. (2015). Crossing frontiers in tackling pathways of biological invasions. Bioscience 65, 769-782. doi: 10.1093/biosci/biv082

European Commission (2014). Turkey Progress Report. COM (2014) 700 final of 8.10.2014. Available online at: http://ec.europa.eu/enlargement/ pdf/key_documents/2014/20141008-turkey-progress-report_en.pdf (accessed September 19, 2019).

European Union (2014). Regulation (EU) No 1143/2014 of the European Parliament and of the Council of 22 October 2014 on the prevention and management of the introduction and spread of invasive alien species. OJEU $57,35-55$.

FAO (2019). Fishery and Aquaculture Country Profiles: The Republic of Turkey. Available online at: http://www.fao.org/fishery/facp/TUR/en (accessed 23 July, 2020).

Fausch, K. D. (1988). Tests of competition between native andintroduced salmonids in streams: what have we learned? Can. J. Fish. Aquat. Sci. 45, 2238-2246. doi: 10.1139/f88-260

Fausch, K. D. (2007). Introduction, establishment and effects of nonnative salmonids: considering the risk of rainbow trout invasion in the United Kingdom. J. Fish Biol. 71, 1-32. doi: 10.1111/j.1095-8649.2007.01682.x

Fausch, K. D., Taniguchi, Y., Nakano, S., Grossman, G. D., and Townsend, C. R. (2001). Flood disturbance regimes influence rainbow trout invasion success among five Holarctic regions. Ecolol. Appl. 11, 1438-1455. doi: 10.1890/10510761(2001)011[1438:FDRIRT]2.0.CO;2

Frankham, R., Ballou, J. D., Dudash, M. R., Eldridge, M. D., Fenster, C. B., and Lacy, R. C. (2012). Implications of different species concepts for conserving biodiversity. Biol. Conserv. 153, 25-31. doi: 10.1016/j.biocon.2012.04.034

Freyhof, J. (2019a). Salmo abanticus. The IUCN Red List of Threatened Species. Available online at: https://dx.doi.org/10.2305/IUCN.UK.20191.RLTS. T19515210A19849316.en (accessed 26 August, 2020).

Freyhof, J. (2019b). Salmo opimus. The IUCN Red List of Threatened Species. Available online at: https://dx.doi.org/10.2305/IUCN.UK.2019-1.RLTS. T19516862A19849331.en (accessed 27 August, 2020).

Galil, B. (2011). "Mediterranean sea: invasions," in Encyclopedia of Biological Invasions, eds D. Simberloff, and M. Rejmánek (Berkeley and Los Angeles, CA: University of California Press), 379-385.

Gallardo, B., Clavero, M., Sánchez, M. I., and Vilà M. (2016). Global ecological impacts of invasive species in aquatic ecosystems. Glob. Chang. Biol. 22, 151-163. doi: $10.1111 / \mathrm{gcb} .13004$

GBIF.org (2020). GBIF Occurrence Download 27 February 2020. doi: 10.15468/dl.r7ht8c

Glamuzina, B., Tutman, P., Nikolić, V., Vidović, Z., Pavličević, J., Vilizzi, L., et al. (2017). Comparison of taxon-specific and taxon-generic risk screening tools for identifying potentially invasive non-native fishes in the River Neretva catchment (Bosnia and Herzegovina and Croatia). River Res. Appl. 33, 670-679. doi: $10.1002 /$ rra.3124

Hasegawa, K. (2020). Invasions of rainbow trout and brown trout in Japan: a comparison of invasiveness and impact on native species. Ecol. Freshw. Fish. 29, 419-428. doi: 10.1111/eff.12534

Hill, J. E., Copp, G. H., Hardin, S., Lawson, M. K., Lawson, L. L., Tuckett, Q. M., et al. (2020). Comparing apples to oranges and other misrepresentations of the risk screening tools FISK and AS-ISK - a rebuttal of Marcot et al. (2019). Manag. Biol. Invasion 11, 325-341. doi: 10.3391/mbi.2020.11.2.10

Hoffmann, B. D., and Broadhurst, L. M. (2016). The economic cost of managing invasive species in Australia. NeoBiota 31, 1-18. doi: 10.3897/neobiota.31. 6960

Houde, A. L. S., Wilson, C. C., and Neff, B. D. (2015). Competitive interactions among multiple non-native salmonids and two populations of Atlantic salmon. Ecol. Freshw. Fish. 24, 44-55. doi: 10.1111/eff.12123

Hulme, P. E., Bacher, S., Kenis, M., Klotz, S., Kühn, I., Minchin, D., et al. (2008). Grasping at the routes of biological invasions: a framework for integrating pathways into policy. J. Appl. Ecol. 45, 403-414. doi: $10.1111 / j .1365-2664.2007 .01442 . x$

IPCC (2005). Guidance Notes for Lead Authors of the IPCC Fourth Assessment Report on Addressing Uncertainties. Intergovernmental Panel on Climate
Change, WMO and UNEP. Available online at: https://www.ipcc.ch/site/assets/ uploads/2018/02/ar4-uncertaintyguidancenote-1.pdf

Iyigun, C., Türkeş, M., Batmaz, I., Yozgatligil, C., Purutçuoglu, V., Kartal Koç, E., et al. (2013). Clustering current climate regions of Turkey by using a multivariate statistical method. Theor. Appl. Climatol. 114, 95-106. doi: 10.1007/s00704-012-0823-7

Ju, R. T., Li, X., Jiang, J. J., Wu, J., Liu, J., Strong, D. R., et al. (2020). Emerging risks of non-native species escapes from aquaculture: Call for policy improvements in China and other developing countries. J. Appl. Ecol. 57, 85-90. doi: 10.1111/1365-2664.13521

Kalayci, G., Ozturk, R. C., Capkin, E., and Altinok, I. (2018). Genetic and molecular evidence that brown troutSalmo truttabelonging to the Danubian lineage are a single biological species. J. Fish Biol. 93, 792-804. doi: 10.1111/jfb.13777

Killi, N., Tarkan, A. S., Kozic, S., Copp, G. H., Davison, P. I., and Vilizzi,. L. (2020). Risk screening of the potential non-native jellyfishes in the Mediterranean Sea. Mar. Pollut. Bull. 150:110728. doi: 10.1016/j.marpolbul.2019.110728

Kottelat, M. (1997). European freshwater fishes. An heuristic checklist of the freshwater fishes of Europe (exlusive of former USSR), with an introduction for non-systematists and comments on nomenclature and conservation. Biologia (Bratislava) 52, 1-271.

Koutsikos, N., Vardakas, L., Zogaris, S., Perdikaris, C., Kalantzi, O., and Economou, A. N. (2019). Does rainbow trout justify its high rank among alien invasive species? Insights from a nationwide survey in Greece. Aquat. Conserv. 29, 409-423. doi: 10.1002/aqc.3025

Lehner, B., and Grill, G. (2013). Global river hydrography and network routing: baseline data and new approaches to study the world's large river systems. Hydrol. Process. 27, 2171-2186. doi: 10.1002/hyp. 9740

Lök, A., Lök, A., and Küçükdermenci, A. (2018). "The status of fisheries and aquaculture production in Turkey," in Proceedings of the 3rd International Congress on Applied Ichthyology and Aquatic Environment (Volos), 258-261.

Lowe, S., Browne, M., Boudjelas, S., and De Poorter, M. (2000). 100 of the World's Worst Invasive Alien Species: A Selection From the Global Invasive Species Database. Published by The Invasive Species Specialist Group (ISSG) a specialist group of the Species Survival Commission (SSC) of the World Conservation Union (IUCN). Available online at: www.issg.org/booklet.pdf

Manel, S., Williams, H. C., and Ormerod, S. J. (2001). Evaluating presence-absence models in ecology: the need to account for prevalence. J. Appl. Ecol. 38, 921-931. doi: 10.1046/j.1365-2664.2001.00647.x

Marcot, B. G., Hoff, M. H., Martin, C. D., Jewell, S. D., and Givens, C. E. (2019). A decision support system for identifying potentially invasive and injurious freshwater fishes. Manag. Biol. Invasion 10, 200-226. doi: $10.3391 / \mathrm{mbi}$.2019.10.2.01

Meinesz, A., and Hesse, B. (1991). Introduction et invasion de l'algue tropicale Caulerpa taxifolia en Mediterranee nord-occidentale. Oceanol. Acta $14,415-426$.

Muhlfeld, C. C., Kalinowski, S. T., Mcmahon, T. E., Taper, M. L., Painter, S., Leary, R. F., et al. (2009). Hybridization rapidly reduces fitness of a native trout in the wild. Biol. Lett. 5, 328-331. doi: 10.1098/rsbl.2009.0033

Ninua, L., Tarkhnishvili, D., and Gvazava, E. (2018). Phylogeography and taxonomic status of trout and salmon from the Ponto-Caspian drainages, with inferences on European Brown Trout evolution and taxonomy. Ecol. Evol. 8, 2645-2658. doi: 10.1002/ece3.3884

Peel, M. C., Finlayson, B. L., and McMahon, T. A. (2007). Updated world map of the Köppen- Geiger climate classification. Hydrol. Earth Syst. Sci. Discuss. 4, 439-473. doi: 10.5194/hessd-4-439-2007

Perdikaris, C., Koutsikos, N., Vardakas, L., Kommatas, D., Simonović, P., Paschos, I., et al. (2016). Risk screening of non-native, translocated and traded aquarium freshwater fishes in Greece using Fish Invasiveness Screening Kit. Fish. Manag. Ecol. 23, 32-43. doi: 10.1111/fme.12149

Phillips, S. J., Anderson, R. P., and Schapire, R. E. (2006). Maximum entropy modeling of species geographic distributions. Ecol. Modell. 190, 231-259. doi: 10.1016/j.ecolmodel.2005.03.026

Pimentel, D., Zuniga, R., and Morrison, D. (2005). Update on the environmental and economic costs associated with alien-invasive species in the United States. Ecol. Econ. 52, 273-288. doi: 10.1016/j.ecolecon.2004.10.002

$\mathrm{R}$ Core Team (2020). R: A language and environment for statistical computing. Vienna: R Foundation for Statistical Computing. Available online at: https:// www.R-project.org/ 
Raffini, F., Bertorelle, G., Biello, R., D’urso, G., Russo, D., and Bosso, L. (2020). From Nucleotides to satellite imagery: approaches to identify and manage the invasive pathogen Xylella fastidiosa and its insect vectors in Europe. Sustainability 12:4508. doi: 10.3390/su12114508

Rahel, F. J., and Nibbelink, N. P. (1999). Spatial patterns in relations among brown trout (Salmo trutta) distribution, summer air temperature, and stream size in Rocky Mountain streams. Can. J. Fish. Aquat. Sci. 56, 43-51. doi: 10.1139/f99-210

Rahel, F. J., and Olden, J. D. (2008). Assessing the effects of climate change on aquatic invasive species. Conserv. Biol. 22, 521-533. doi: $10.1111 / \mathrm{j} .1523-1739.2008 .00950 . x$

Reichard, S. H., and White, P. (2001). Horticulture as a pathway of invasive plant introductions in the United States. Bioscience 51:103. doi: 10.1641/00063568(2001)051[0103:HAAPOI]2.0.CO;2

Rejmánek, M. (2011). "Invasiveness," in Encyclopedia of Biological Invasions, eds D. Simberloff, and M. Rejmánek (Berkeley and LosAngeles, CA: University of California Press), 379-385.

Robin, X., Turck, N., Hainard, A., Tiberti, N., Lisacek, F., Sanchez, J.-C., et al. (2011). pROC: an open-source package for R and S+ to analyze and compare ROC curves. BMC Bioinformatics 12:77. doi: 10.1186/1471-2105-12-77

Rodríguez-Merino, A., García-Murillo, P., Cirujano, S., and Fernández-Zamudio, R. (2018). Predicting the risk of aquatic plant invasions in Europe: how climatic factors and anthropogenic activity influence potential species distributions. J. Nat. Conserv. 45, 58-71. doi: 10.1016/j.jnc.2018.08.007

Roy, H. E., Rabitsch, W., Scalera, R., Stewart, A., Gallardo, B., Genovesi, P., et al. (2018). Developing a framework of minimum standards for the risk assessment of alien species. J. Appl. Ecol. 55, 526-538. doi: 10.1111/1365-2664.13025

Scott, D., and Irvine, J. R. (2000). Competitive exclusion of brown trout Salmo trutta L., by rainbow trout Oncorhynchus mykiss Walbaum, in lake tributaries, New Zealand. Fish. Manag. Ecol. 7, 225-237. doi: 10.1046/j.1365-2400.2000.00177.x

Seiler, S. M., and Keeley, E. R. (2009). Competition between native and introduced salmonid fishes: cutthroat trout have lower growth rate in the presence of cutthroat-rainbow trout hybrids. Can. J. Fish. Aquat. Sci. 66, 133-141. doi: 10.1139/F08-194

Simberloff, D. (2011). "Rodents (Other)," in Encyclopedia of Biological Invasions, eds D. Simberloff, and M. Rejmánek (Berkeley and Los Angeles, CA: University of California Press), 379-385. doi: 10.1525/97805209 48433

Simberloff, D., Martin, J.-L., Genovesi, P., Maris, V., Wardle, D. A., Aronson, J. et al. (2013). Impacts of biological invasions: what's what and the way forward. Trends Ecol. Evol. 28, 58-66. doi: 10.1016/j.tree.2012.07.013

Stanković, D., Crivelli, A. J., and Snoj, A. (2015). Rainbow trout in Europe: introduction, naturalization, and impacts. Rev. Fish. Sci. Aquac. 23, 39-71. doi: 10.1080/23308249.2015.1024825

Stoumboudi, M., Barbieri, R., and Kalogianni, E. (2017). First report of an established population of Oncorhynchus mykiss (Walbaum, 1792) (Salmonidae) on the Island of Crete, Greece. Acta Zool. Bulg. Suppl. 9, 99-104

Tarkan, A. S., Marr, S. M., and Ekmekçi, F. G. (2015). Non-native and translocated freshwater fish species in Turkey. FISHMED 3, 1-28. doi: 10.29094/FiSHMED.2015.003

Tarkan, A. S., Sari, H. M., Ilhan, A., Kurtul, I., and Vilizzi, L. (2017b). Risk screening of nonnative and translocated freshwater fish species in a Mediterranean-type shallow lake: Lake Marmara (West Anatolia). Zool. Middle East 63, 48-57. doi: 10.1080/09397140.2017.1269398

Tarkan, A. S., Vilizzi, L., Top, N., Ekmekçi, F. G., Stebbing, P. D., and Copp, G. H. (2017a). Identification of potentially invasive freshwater fishes, including translocated species, in Turkey using the Aquatic Species Invasiveness Screening Kit (AS-ISK). Int. Rev. Hydrobiol. 102, 47-56. doi: 10.1002/iroh.201601877

Tarkan, A. S., Yoğurtçuoğlu, B., Ekmekçi, F. G., Clarke, S. A., Wood, L. E., Vilizzi, L., et al. (2020). First application in Turkey of the European Non-native Species in Aquaculture Risk Analysis Scheme to evaluate the farmed non-native fish, striped catfish Pangasianodon hypophthalmus. Fish Manag. Ecol. 27, 123-131. doi: $10.1111 /$ fme. 12387

Taylor, H. R., Dussex, N., and van Heezik, Y. (2017). Bridging the conservation genetics gap by identifying barriers to implementation for conservation practitioners. Glob. Ecol. Conserv. 10, 231-242. doi: 10.1016/j.gecco.2017.04.001

TUIK (2014). Su Ürünleri Istatistikleri/Fishery Statistics 2013. Ankara: Turkish Statistical Institute, Printing Division, 75.

Turan, D., Dogan, E., Kaya, C., and Kanyilmaz, M. (2014b). Salmo kottelati, a new species of trout from Alakir Stream, draining to the Mediterranean in southern Anatolia, Turkey (Teleostei, Salmonidae). Zookeys 462, 135-151. doi: $10.3897 /$ zookeys.462.8177

Turan, D., Kalayci, G., Bektaş, Y., Kaya, C., and Bayçelebi, E. (2020). A new species of trout from the northern drainages of Euphrates River, Turkey (Salmoniformes: Salmonidae). J. Fish Biol. 96, 1454-1462. doi: $10.1111 /$ jfb.14321

Turan, D., Kottelat, M., and Bektaş Y. (2011). Salmo tigridis, a new species of trout from Tigris River, Turkey (Teleostei: Salmonidae). Zootaxa 2993, 23-33. doi: 10.11646/zootaxa.2993.1.2

Turan, D., Kottelat, M., and Engin, S. (2010). Two new species of trouts, resident and migratory, sympatric in streams of northern Anatolia (Salmoniformes: Salmonidae). Ichthyol. Explor. Freshw. 20, 289-384.

Turan, D., Kottelat, M., and Engin, S. (2012). The trouts of the Mediterranean drainages of southern Anatolia, Turkey, with description of three new species (Teleostei: Salmonidae). Ichthyol. Explor. Freshw. 23, 219-236.

Turan, D., Kottelat, M., and Engin, S. (2014a). Two new species of trouts from the Euphrates drainage, Turkey (Teleostei: Salmonidae). Ichthyol. Explor. Freshw. 24, 275-287.

Turan, D., Kottelat, M., and Kaya, C. (2017). Salmo munzuricus, a new species of trout from the Euphrates River drainage, Turkey (Teleostei: Salmonidae). Ichthyol. Explor. Freshw. 28, 55-63.

Uyan, U., Oh, C.-W., Tarkan, A. S., Top, N., Copp, G. H., and Vilizzi, L. (2020). Risk screening of the potential invasiveness of non-native marine fishes for South Korean coastal waters. Mar. Pollut. Bull. 153:111018. doi: 10.1016/j.marpolbul.2020.111018

Vilizzi, L., Piria, M., Tarkan, A. S., Tricarico, E., Vardakas, L., and Copp, G. H. (2019). "Risk analysis tools for assessing the potential risks posed by non-native species in the eastern Mediterranean region," in 14. International Congress on the Zoogeography and Ecology of Greece and Adjacent Regions (Thessaloniki).

Weigel, D. E., Peterson, J. T., and Spruell, P. (2003). Introgressive hybridization between native cutthroat trout and introduced rainbow trout. Ecol. Appl. 13, 38-50. doi: 10.1890/1051-0761(2003)013[0038:IHBNCT]2.0.CO;2

Yoğurtçuoğlu, B., Kaya, C., and Freyhof, J. (2020). Freshwater fishes of the anatolian midwestern black sea basin. Ichthyol. Explor. Freshw. 30, 1-20. doi: 10.23788/IEF-1152

Zieba, G., Vilizzi, L., and Copp, G. (2020). How likely is Lepomis gibbosus to become invasive in Poland under conditions of climate warming? Acta Ichthyol. Piscat. 50, 35-51. doi: 10.3750/AIEP/02390

Conflict of Interest: The authors declare that the research was conducted in the absence of any commercial or financial relationships that could be construed as a potential conflict of interest.

Copyright (c) 2021 Yoğurtçuoğlu, Bucak, Ekmekçi, Kaya and Tarkan. This is an open-access article distributed under the terms of the Creative Commons Attribution License (CC BY). The use, distribution or reproduction in other forums is permitted, provided the original author(s) and the copyright owner(s) are credited and that the original publication in this journal is cited, in accordance with accepted academic practice. No use, distribution or reproduction is permitted which does not comply with these terms. 